ABSORPTION SPECTRA OF SOLUTIONS OF LIQUID AMMONIA, ETC. I327

[CONTRIBUTion From the Chemical Department OF the UNIVERSITy OF CALIFORNia.]

\title{
THE ABSORPTION SPECTRA OF THE BLUE SOLUTIONS OF CERTAIN ALKALI AND ALKALINE EARTH METALS IN LIQUID AMMONIA AND IN METHYLAMINE.
}

\author{
By G. E. Grbson and W. L. Argo.
}

Received June 13, 1918.

Introduction.

In a paper by the authors on the absorption spectra of solutions of sodium and magnesium in liquid ammonia, ${ }^{1}$ it was shown that the blue color of these solutions is not only of the same shade as far as the eye can judge, but also that the absorption spectra measured by the spectrophotometer are identical in type, within the limits of experimental error. Thus a solution of sodium and a solution of magnesium chosen of such concentration that they absorb to an equal extent at any one wave length will absorb to an equal extent at all wave lengths in the visible spectrum. Since solutions of other alkali and alkaline earth metals in liquid ammonia, methylamine and ethylamine, and even of calcium in a molten mixture of sodium and potassium chlorides give solutions which to the eye appear to be of the same shade of blue, the explanation was suggested, in accordance with the theory proposed by $\mathrm{Kraus}^{2}$ to account for the electrical properties of such solutions, that the color in all these solutions is due to the same substance, namely, the electron liberated from the metal by the dissociation

$$
\mathrm{Me}=\mathrm{Me}^{+}+\Theta,
$$

where $\mathrm{Me}^{+}$is the cation present in solutions of salts of the metal and $\Theta$ is an electron. The ions $\mathrm{Me}^{+}$and $\ominus$ may be combined to a greater or less extent with the molecules of the solvent, but Kraus ${ }^{3}$ concludes from measurements of the electromotive force of concentration cells that at least one-third of the current in a normal solution of sodium in liquid ammonia is carried by the unsolvated electrons. The conduction is, therefore, to a considerable extent metallic in character in the more concentrated solutions. In more dilute solutions the electrons are to a large extent associated with the solvent molecules.

If we assume dissociation into electrons, the blue color of these metallic solutions may then be due to one (or more) of the following substances: (a) un-ionized molecules or atoms of the metal, $(b)$ unsolvated electrons, (c) solvated electrons. Since a blue color is obtained with any combination of solvent and metallic solute which has yet been tried, the evidence appears at first sight to favor assumption $(b)$, that the color is due to

1 Phys. Rev. N. S., 7, 33 (1916).

${ }^{2}$ This Journal, 29, 1557 (1907).

3 Kraus, Ibid., 36, 864 (1914). 
unsolvated electrons. From the electron theory of metallic dispersion, however, it is possible to calculate the number and mobility of the unsolvated (free) electrons in a solution (and hence its conductivity) from the absorption spectrum, providing the color is solely due to these unsolvated electrons. In our former paper it was shown in this way that the absorption curves of sodium and magnesium in liquid ammonia could not be ascribed solely to unsolvated electrons, as the calculation from the dispersion theory on this assumption yields impossible results for the conductivity and the number of electrons. Since sodium and magnesium give identical absorption spectra in liquid ammonia it seems unlikely that the color should be due to un-ionized atoms of the metal. The evidence is, therefore, in favor of the assumption (c) that the color is due to solvated electrons. This conclusion is borne out by the present investigation in which numerous measurements at varying concentrations and temperatures have been made with solutions of metals in ammonia and in methylamine.

\section{Experimental Details.}

The preparation of a solution of an alkali metal in anhydrous ammonia or methylamine is troublesome on account of the great reactivity of the metals and the high dissolving power and volatility of the solvents. It has been our experience that solutions prepared from metals which had been partially oxidized by contact with air fade very rapidly, and it seems probable that the hydroxide formed in this way has a catalytic effect upon the action of the metal with the solvent. This latter reaction, namely, for sodium,

$$
\mathrm{Na}+\mathrm{NH}_{3}=\mathrm{NaNH}_{2}+1 / 2 \mathrm{H}_{2},
$$

is very difficult to prevent and when the fading due to it is rapid, absorption measurements cannot be performed with accuracy. The formation of amide can be almost completely stopped, however, if the solvent is pure, if there is no trace of hydroxide or oxide in contact with the solution and if the temperature is kept below $-60^{\circ}$. Accurate measurements were obtained only by developing a technique to observe all these requirements.

The chief difficulty in the use of anhydrous ammonia and methylamine lies in the fact that mechanically closed absorption cells cannot be employed. Cements also are either too moist or are attacked by the solvent. As a result of many attempts we were led to the use of a type of apparatus which involves so many unfamiliar features that it seems best to describe its construction in considerable detail.

The Absorption Cell.-In the earlier measurements we made use of a cell consisting of quartz windows sealed into a quartz tube. The technique for the construction of such a cell has been fully described in our previous 
paper. ${ }^{1}$ The scarcity of optically clear fused quartz for the construction of the windows made it advisable, however, to experiment with glass to see if it was possible to develop a technique for sealing in a plane-glass window into a glass tube without the distortion of the window which is ordinarily obtained. It is exceedingly difficult to accomplish this result when the tube and the window are of the same kind of glass. But we found that a glass window cut from a microscope slide can be sealed into a lead glass tube without distortion of the face of the window except for a distance of about a millimeter inward from the edge. The operation is as follows: The lead glass tube $a$, Fig. I, diameter about $\mathrm{I} \mathrm{cm}$. was clamped vertically. The window $b$, resting on the funnel-shaped end of the glass tube $c$ was adjusted in a position approximately at right angles to the axis of the tube by moving the stopper $d$. The tube was warmed with a large, soft gas flame round the window during the whole sealing process. By means of a small, soft, oxy-gas flame ${ }^{2}$ the lead glass tube

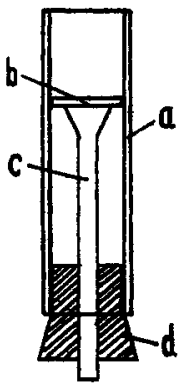

Fig. I. was heated at one spot till quite soft and pressed against the window with an iron rod. In this way the lead glass could be cemented to the window and fused with it completely although the window itself had been softened only at the outer edge. Distortion of the plane surface of the window was therefore almost completely prevented. The operation was repeated until the whole circumference of the window was in contact with the tube, forming a perfectly transparent junction. Any spots which had been overlooked were easily detected by the presence of the unchanged ground glass edge of the window. After the sealing was complete the whole tube was warmed thoroughly with the soft gas flame and annealed in warm asbestos wool. The edge of the window viewed at right angles to the axis of the tube was marked only by a few bubbles which had been entrapped, and the window viewed along the axis of the tube was almost invisible. Distortion was tested for by observing the reflection of straight edges from the surfaces of the window and it was found that no distortion could be detected except for a ring of about one mm. around the circumference. After some practice we were able in most cases to complete the operation without cracks appearing. In the few cases where the apparatus cracked at the junction the break ran across the window instead of round it, showing that the glass at the junction was really homogeneous. ${ }^{3}$

1 Phys. Rev. N. S., 7, 33 (1916).

${ }^{2} \mathrm{~A}$ hot, quiet, diffused oxy-gas flame can be obtained by reversing the gas and oxygen tubes on an ordinary hand blow-pipe (dental torch).

${ }^{3}$ Lead glass was chosen for two reasons: because of its low melting point and because of its high coefficient of expansion. On cooling, the lead glass tube shrinks 
In making the absorption cell it was necessary to seal in two parallel windows by this method. A lead glass tube $\mathrm{I} \mathrm{cm}$. in diameter was fitted with a smaller lead glass tube at right angles to its axis. One window was sealed, just above the opening of the side tube, in the manner already described. While the whole tube was kept hot with the gas flame the support for the window was removed, a second window placed on it and the support readjusted so as to bring this window just below the entrance of the side tube. A small electric light was then held at a distance of about ${ }_{4}$ feet vertically above the tube and the lower window was adjusted by means of the support until the two reflections from its faces coincided with the two from the upper windows. ${ }^{1}$

The operation of sealing in the lower window was then completed as before. While the tube was still hot the optical test with the electric light was repeated. Frequently it was found that a slight shift had taken place and in such cases the tube was heated between the two windows until soft and the four images were easily brought to coincide again. After the glass had hardened the apparatus was annealed in asbestos wool.

It was necessary to leave at least $5 \mathrm{~mm}$. of tube projecting beyond the windows during the sealing-in process in order to protect them from distortion by direct contact with the oxy-gas flame. We had considerable difficulty at first in removing the excess tubing. A rotating steel disc charged with oil and emery sometimes worked satisfactorily, but in many cases the vibration caused a crack to run across the face of the window. It was found, however, that the tube could somewhat laboriously be sawed off by hand, with the back of a hack saw blade, charged with oil and emery, if care was taken not to exert any pressure on the blade during the process.

Cells made in this way, with windows $I \mathrm{~cm}$. in diameter and with a distance of I cm. between windows have frequently been used under a pressure of 8 atmospheres. They can be cooled in liquid air and heated to their melting point without breakage, if the change of temperature is gradual. They are perfectly gas-tight when the seal is made carefully.

We were, therefore, able to substitute cells of this type for the quartz cell which we had used previously. Occasional breakages could thus be remedied in a shorter time and at much smaller expense.

The Dewar Vessel.--A much more complicated application of the same method was necessary in the construction of a Dewar vessel through which optical measurements could be made. The method of reflection of the

against the soda glass window and the unavoidable strain is applied uniformly and does not cause fracture. The oxy-gas flame was used to prevent reduction of the lead glass.

1 The microscope slides from which the windows were cut were selected so that the two images from the slide practically coincided when the source of light was placed on the normal from the eye to the plane of the slide. 
light into and out of an ordinary Dewar vessel involves a great many uncertainties, particularly as the contents of the vessel must be kept cold. It was therefore decided to insert windows of the type used in the absorption cell into the inner and outer walls of the Dewar vessel. It was necessary that these windows should be undistorted, that the junctions should be vacuum-tight and that all 4 windows should be parallel to each other within narrow limits. The various stages in the construction are shown in the diagrams, Figs. 2, 3 and 4 .

The inner tube was instructed as shown 1. Fig. 2. It con-

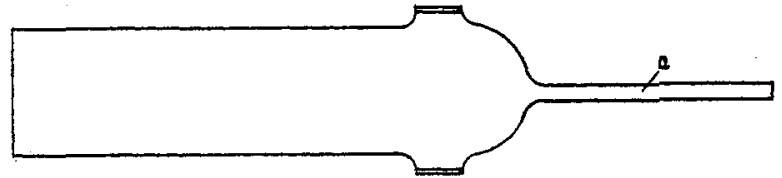

Fig. 2. sisted of a lead glass tube (inner diameter $35 \mathrm{~mm}$., walls I mm. thick) with lead glass side tubes sealed on $2 \mathrm{~cm}$. from the lower end, and a lead

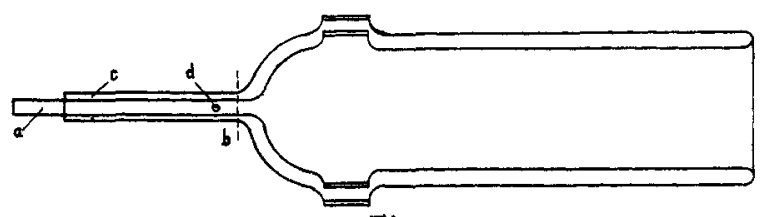

Fig. 3. 'glass tube, $a$, about 5 mm. in diameter sealed to the bottom. Into the side tubes windows were sealed exactly as in the

preparation of the absorption cell. The side tubes were then trimmed down close to the windows with the emery-charged hack saw blade as before.

The outer tube, somewhat larger but otherwise identical with the inner tube, was constructed as shown in Fig. 2. Side tubes were inserted on a lead glass tube $48 \mathrm{~mm}$. in diameter, windows sealed in and the extra glass trimmed off as before.

In the preparation of both these tubes great precautions were necessary to keep them uniformly heated during the sealing process and to anneal them thoroughly. Once the operation was completed, however, they were quite stable and showed no tendency to crack at any of the seals.

The small tube was then inserted into the large one and adjusted as before with the aid of the small electric lamp until all 4 windows were parallel. While the tubes were held in this position the glass tube $a$, sealed to the bottom of the inner tube, was cemented with shellac into the corresponding tube $c$ of the

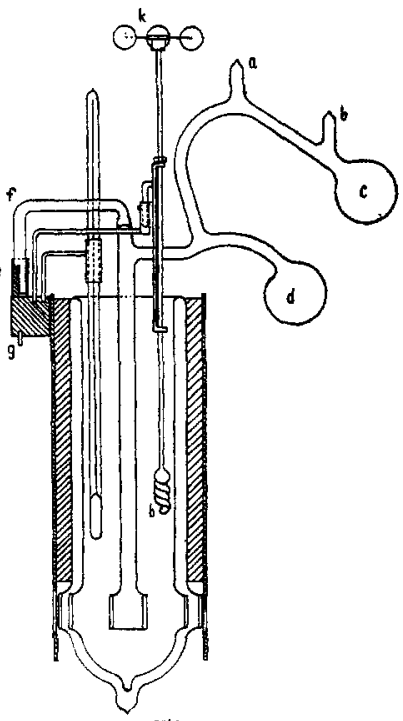

Fig. 4 
outer tube, and there was then no danger of the two tubes getting out of alignment.

The next step was the sealing together of the mouths of the inner and outer tubes. In preparation for this the windows and about two inches of the tube above the windows were thoroughly protected from heat by wrapping with asbestos wool and asbestos cord. The windows of the inner tube were likewise protected by packing asbestos wool into it to within about an inch of the mouth. The open ends of the two tubes after being carefully heated until they softened were bent over until the made contact. It was possible here to apply the usual glassblower's procedure, except that the oxy-gas flame was used as before. A subsidiary large gas flame served to prevent cracking at the parts of the joint not touched by the flame. The blowing was done through the glass tube $a$ (Fig. 3), the air entering the Dewar vessel through a small hole, $d$, in the tube left for this purpose.

After the seal was complete the whole end of the vessel was softened and the images of the electric light were again observed. They were found to be in good position, but had they been displaced it would have been a simple matter to soften the supporting cement and make the necessary readjustment. The whole apparatus was then annealed carefully.

In order to silver and evacuate the vessel it was necessary to remove the supporting lead glass tube $a$, attached to the inner vessel. The tubulation of the outer tube was cut off at $b$, and after the tube $a$ had been sealed off and the silvering completed a second tubulation was made by sealing on a new lead glass tube at $b$. The silvering was carried out according to the directions given in Ostwald-Luther's Handbuch. ${ }^{1}$ In order to remove the silver which had deposited on the windows themselves we inserted a small glass pipet bent to conform to the shape of the cell, with a cotton swab tied to its tip, and containing a little dilute nitric acid. The silver was dissolved and wiped off the windows and the residual nitric acid was washed out quickly with distilled water.

The vessel was then ready for evacuation. The tubulation was sealed on, and a connection made with a mercury pump through a U-tube which was immersed in liquid air to remove the mercury vapor. While the evacuation was proceeding the whole vessel was surrounded by oil and warmed to $200^{\circ}$. A higher temperature was found inadvisable because of the tendency of the silver to detach from the glass. After evacuating for about an hour the tubulation was seaied off close to the bottom of the vessel, which was then ready for use. To protect it from breakage the vessel was enclosed in a copper jacket lined with felt.

Supports for Absorption Cell and Dewar Vessel. - It was then necessary to devise a support for the absorption cell in the Dewar vessel of such a

i. Ostwald-Luther, Handbuch, 3rd edition, p. 392. 
character that the 4 windows of the Dewar vessel and the two windows of the cell should be parallel within narrow limits. For this purpose a glass-brass connection was devised. A brass collar had been mounted on the copper jacket of the Dewar vessel. To this collar was soldered a brass socket, $e$, fitted with a spring. The socket was so constructed that a rod of glass, $f$, ground plane on one side, when fitted into the socket, could not be rotated about its longitudinal axis. This rod of glass was then sealed to the absorption cell and, by softening it near its junction with the cell, we were able to adjust the position of the cell within the Dewar vessel until the images of the electric light filament reflected from all six windows, were superimposed. It was now possible to remove and replace the cell rapidly without altering its adjustment with respect to the Dewar vessel.

There remained only the question of supporting the Dewar vessel and absorption cell on the framework of the spectrophotometer. In the spectrophotometer which we used the comparison of the intensity of a beam of light which had passed through the absorbing solution with one which had not passed through, was made by two settings of the instrument, in which the absorption cell was traversed by the right-hand and left-hand beam alternately. This fact required the construction of a frame in which the apparatus could be adjusted rapidly in either position in such a way that the plane of the windows remained at right angles to the axis of the beam. For this purpose we clamped to the spectrophotometer base a framework fitted with 4 . holes in such a position that into either pair we could fit the two little pins $g$ on the under side of the brass collar of the Dewar vessel. After being so fitted the Dewar vessel windows were finally brought into the correct position by adjustment of the framework for horizontal correction and by tilting the Dewar vessel slightly by means of set screws in the framework for vertical correction. As these adjustments were permanent it was a simple matter to change the cell from one side to the other in the course of the readings.

Temperature Control.-As we desired to make our readings at temperatures at which the fading due to the reaction of the metal with the solvent was small, it was necessary to introduce some cooling agent. In our earlier experiments with the quartz cell we had used liquid ammonia at its boiling point, $-33.6^{\circ}$, but the fading at such temperatures was quite marked and necessitated rapid and often incomplete readings. We first attempted to cool the liquid ammonia in the Dewar vessel to a lower temperature by means of a carefully regulated supply of liquid air running through a copper coil, but the difficulties of regulation and of obtaining at all times the requisite amount of liquid air made it advisable to use some other cooling material. After some experiments it was found 
that a very constant temperature could be obtained by placing in the Dewar vessel a thin-walled copper receptacle, semi-cylindrical in shape, into which was packed a mixture of ether and solid carbon dioxide. Temperatures could be varied by varying the size of the copper receptacle or by lining it with hard rubber to increase the lag in heat flow. Most of our determinations were made at about $-65^{\circ}$, which is an easy temperature to maintain, and is low enough to insure almost complete absence of fading. In our latest measurements, of which sodium in methylamine, Series $\mathrm{XV}$ and $\mathrm{XVI}$, are a type, the variation in temperature was never more than $I^{\circ}$; this result was attained by refilling the jacket with carbon dioxide at regular intervals of 5 minutes.

The choice of the liquid used in the Dewar vessel gave us some difficulty at first. Ammonia was not convenient; gasoline became turbid after a time, due to condensation of ice in it; and alcohol became too viscous, particularly after it had absorbed moisture from the air. A mixture of one volume of alcohol with 3 volumes of ether was found to be extremely satisfactory. It remained mobile at $-65^{\circ}$; traces of moisture dissolved instead of forming finely powdered snow, and, at low temperatures, there was no loss by evaporation.

Stirring of the Bath and Removal of Condensed Ice from the Windows. -The liquid was stirred by a small glass screw, $h$, Fig. 4 , driven by a blast of air against little cups, $k$, mounted as on an anemometer. This arrangement had the advantage of doing away with any connections such as belts, between the apparatus and a separate motor. The airblast was supplied from a nozzle mounted so that the stirrer operated when the cell was in either of its positions in the spectrophotometer.

During the course of a measurement, if no precautions had been taken, moisture would have condensed on the outer windows of the Dewar vessel. This was avoided by arranging glass jets in such a position that a stream of dry air played against each of the outer windows when the Dewar vessel was mounted in either position on its spectrophotometer support. Occasionally a few particles of dust accumulated, probably due to vortex action, and therefore every ro minutes during the course of our latest readings the windows were wiped off with a clean cloth.

The Preparation and Storage of the Anhydrous Solvents.-During the exhaustive researches of Franklin and Kraus ${ }^{1}$ upon the use of anhydrous ammonia as a solvent, a satisfactory technique for its storage and use was developed. The ammonia, in their procedure, was distilled from the large commercial container into a smaller tank containing sodium. The soditum which dissolved quickly in the ammonia, removed any traces of water. The distillation served to remove the greater part of the amine impurities as well as all insoluble material and oils. It occurred to us

\footnotetext{
1 Am. Chem. J., 23, 277 (1900); Thrs Journal, 27, 191 (1905).
} 
that it would be more convenient, since we planned to introduce our solvent by distillation in vacuo, to distil the pure anhydrous ammonia from the small storage tank into a glass bulb containing ammonium nitrate which had been dried by several hours' heating at $130^{\circ}$ in vacuo. The resulting Divers' solution, which gave a pressure in the neighborhood of I atmosphere, opened directly into the supply line through a vacuum stopcock. The advantage lay in the fact that glass connections could be used throughout, and there was no danger of explosions due to too sudden opening of the ammonia tank.

It is possible that methylamine could have been stored in much the same manner. Sodium iodide, for instance, is so soluble in methylamine that the vapor pressure is lowered enormously and a solution corresponding to the Divers' solution could be made by distilling dry methylamine on to sodium iodide. Such a solution stored in a glass bulb and opening into the supply line through a mercury stopcock such as that described by Lewis and Kraus ${ }^{1}$ would doubtless have proved exceedingly satisfactory. In our experiments, however, we stored the methylamine in a small steel tank containing potassium ${ }^{2}$ and connected the tank with the supply line through a specially constructed gas-tight steel valve, a glass tube and a glass stopcock. The glass tube was connected to the steel delivery tube of the tank by de Khotinsky cement, which, while it was not attacked rapidly by the methylamine, absorbed it slowly and disintegrated. It was thetefore necessary, after each withdrawal of methylamine, to close the steel valve and evacuate the whole delivery line to protect the cement.

A Typical Operation.-The operations involved in a measurement can best be described by giving a brief account of one of the experiments. The absorption cell, constructed as in the diagram (Fig. 4), was removed from the Dewar vessel and washed with alkali, nitric acid, distilled water and double-distilled water. It was then joined through the tube $a$ to a glass-supply line which could be opened into a dry ammonia reservoir, a dry methylamine reservoir, or a high vacuum line. The cell arms were warmed with a smoky flame and the cell proper with the glass windows was immersed in an oil bath. While the cell was heated up the whole system was thoroughly exhausted. This operation served to remove the adsorbed moisture from the walls of the cell.

The side tube $b$ was then opened and a freshly opened piece of glass capillary tubing containing the metal to be studied was dropped into the bulb $c$. At the same time a side tube leading into a bulb lying in the supply line (not shown in the diagram) was opened and a piece of the same metal was dropped into it. Both openings were then sealed up quickly and the apparatus was evacuated again as quickly as possible.

${ }^{1}$ Lewis and Kraus, This Journal, 32, 1464 (1910).

2 Sodium is not sufficiently soluble in methylamine to dry it rapidly. 
The warming was repeated in the way already described, except that the bulb $c$ containing the metal was not heated until near the end of the operation. Gentle heating then caused the metal in the capillary to melt and by tapping gently it could be shaken out of the capillary.

The whole apparatus was then allowed to cool and the bulb in the supply line was immersed in a carbon dioxide-ether mixture. When the ammonia or methylamine storage tank was opened the gas quickly condensed in this bulb and any traces of moisture remaining were removed by the action of the metal which it contained. The liquid was then distilled into the absorption cell in a similar way and the apparatus was sealed off at $a$. In spite of all precautions it was usually found that a blue solution made from these materials by distilling some of the solvent on to the metal, faded out quickly when it was poured from the upper bulb into the absorption cell proper. The further purification necessitated by this behavior consisted of pouring the solution which had faded into the lower bulb $d$, redistilling the solvent into the upper bulb, and pouring the new solution into the absorption cell again. After this was repeated two or three times it was found that the solution was sufficiently pure to retain an almost constant intensity of color for an hour at $-65^{\circ}$. It is impossible to state definitely what are the impurities which caused the fading. Part was probably due to the catalytic action of the hydroxide or oxide of the metal formed when the metal was introduced into the cell. In addition there seemed to be a residual film of moisture clinging to the wall of the cell. But, by means of the washing and distilling, any impurities were eventually collected in the lower bulb, and the final solution consisted almost entirely of the pure metal and pure solvent.

It is necessary to emphasize the fact that the solution at no time was warmed beyond room temperature because of the marked increase in the rate of the fading reaction which would have resulted. The distillation was performed in each case by immersing in cold alcohol the bulb containing the liquid to be distilled and cooling off the receiving bulb in a carbon dioxide-ether mixture. In addition it was found necessary to cool down the connecting tubes and the absorption bulb itself with the same mixture before pouring the metallic solution into it from the upper bulb. Neglect of any of these precautions resulted in a solution which faded rapidly. ${ }^{1}$

The cell containing blue solution was kept cold in the carbon dioxideether mixture until the Dewar vessel was made ready. The alcoholether solution for the Dewar vessel was filtered, placed in it and cooled down to $-65^{\circ}$ in the manner described above. The absorption cell

1 The effect of varying amounts of impurities on the absorption spectrum is discussed in the section on absorption spectra. 
was then placed in position in the Dewar vessel after rinsing with cold alcohol and ether to free it from adhering carbon dioxide snow.

The actual measurement of the absorption spectrum has been fully described in our previous paper. For the understanding of the symbols used in our tables we shall recapitulate briefly the principles of the method.

The absorption spectrum was measured by means of a spectrophotometer of the type described by Martens and Grünbaum. ${ }^{2}$ A source of light, A (Fig. 5), illuminates the ground glass window B. The light from $B$ passes through two lenses, $\mathrm{C}$, which produce an image of $B$ on each of the slits E, E. The Dewar vessel containing the absorption cell may

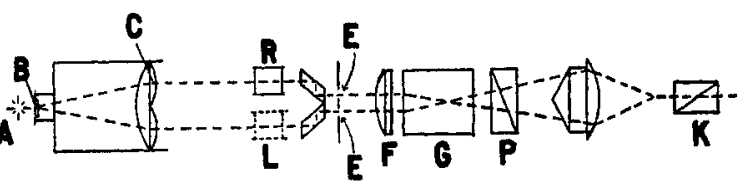

Fig. 5 . be placed in either of the positions $R$ and $L$. After passing through the slits $E, E$ the two beams traverse successively the collimator $F$, the prism $G$, the polarizer $P$ and the analyzer $K$. The analyzer is rotated until the fields illuminated by the two beams appear of equal intensity. The method of reading the spectrophotometer and the niethod of averaging the readings were essentially the same as those of Martens and Grünbaum. Martens and Grünbaum compare the cell containing the colored solution with a cell of the same dimensions containing the pure solvent. This method would have necessitated a duplication of the apparatus. To avoid this the following 4 readings were made:

I. The angle $\alpha_{1}$, with the absorption cell containing pure solvent at $R$ and the space $I$ vacant.

2. The angle $\alpha_{2}$, with the absorption cell containing solvent at $L$ and the space $R$ vacant.

3. The angle $\alpha_{3}$, with the absorption cell containing blue solution at $R$ and the space $L$ vacant.

4. The angles $\alpha_{4}$, with the absorption cell containing blue solution at $L$ and the space $R$ vacant.

From simple optical principles, if we define $\epsilon_{1}$ and $\epsilon_{\circ}$ by the equations

$$
\begin{aligned}
\epsilon_{0} & =\frac{\log \tan \alpha_{2}-\log \tan \alpha_{1}}{d} \\
\epsilon_{1} & =\frac{\log \tan \alpha_{4}-\log \tan \alpha_{3}}{d}
\end{aligned}
$$

it follows that

and

$$
\epsilon_{0}=\epsilon_{\text {solvent }}+K
$$

$$
\epsilon_{1}=\epsilon_{\text {solution }}+K
$$

where $K$ is a constant of the absorption cell. The required difference $\epsilon$

1 Martens and Grünbaum, Ann. d. Phys., 12, 984 (1903). 
between the extinction coefficients of the solution and of the solvent is therefore $\epsilon_{1}-\epsilon_{0}{ }^{1}$

Experimental Error.-The experimental errors involved diminished as the time available for a measurement increased. In our earlier work fading was so rapid that a measurement had to be completed in less than an hour. When it is realized that for each wave length 16 settings were made it is obvious that no exact readings could be obtained. In such cases an error of several per cent. in $\epsilon$ was frequent. But latterly, when fading was diminished and it was possible to check any inconsistent results, the error was reduced to less than $1 \%$. The element of fatigue entered largely into the question of accuracy. It was found that it was very important to have a continual sweep of fresh air into the room.

The greatest difficulty lay in measurements in the blue end of the spectrum. The absorption here was very small and the actual settings were less reliable because of the decrease in brilliancy at these wave lengths. The latter difficulty had a similar effect on the readings at the extreme red end of the spectrum, so that in every case readings at the extremes have the greatest percentage error.

The alkali metals used were samples of Kahlbaum's purest quality. A portion of the metal was freed from adhering petroleum by means of dry filter paper, and heated to fusion in a porcelain dish. The fused metal was then drawn by suction into a heated glass capillary and allowed to solidify. In the case of lithium a capillary of fused silica had to be used owing to the higher melting point of this metal. The capillaries were then sealed and stored until needed for a measurement. The capacity of the capillary was usually determined prior to filling by calibration with mercury so that a portion of metal of the desired amount could be obtained by cutting off a measured length of the capillary, and transferring it as rapidly as possible to the bulb in which the solution was finally prepared. The solutions in liquid ammonia were prepared without the second bulb ( $d$, Fig. 4) and were therefore not purified from hydroxide and amide as described on page 1336. With this device, which was employed in the later measurements, the fading would probably have been eliminated entirely.

\section{The Absorption Spectra of Lithium, Sodium, Potassium, Magnesium and Calcium in Liquid Ammonia.}

Measurements of the absorption spectra of solutions of sodium and magnesium in liquid ammonia have already been published. ${ }^{2}$ These

1 The index of absorption is defined as the fractional diminution in intensity suffered per centimeter by a ray of light passing through the medium. Thus if $J_{\circ}$ is the intensity of a ray of light entering normally a plane slab of the medium the intensity $J$ after $d$ centimeters have been traversed is $J=J_{0}$ 10 $0^{-\epsilon d}$ or $\epsilon=-\left(\log J / J_{0}\right) / d$.

"Phys. Rev. N. S., 7, 3.3 (1916). 
measurements were made with a more primitive type of absorption cell which could not be used at such low temperatures as the one described above. The temperature of these measurements was room temperature for magnesium, and the boiling point of liquid ammonia (about $-33.6^{\circ}$ ) for sodium.

With the new apparatus we have determined in addition the absorption spectra of lithium, potassium and calcium in liquid ammonia. The results of these measurements, together with the data for sodium and magnesium taken from our previous paper, are summarized in Table I. More detailed data for lithium, potassium and calcium are given in Tables II and III at the end of this section.

In Table $I$ the first column contains the values of the wave lengths $\lambda$, in $\mu \mu$, and the subsequent columns the values of $\epsilon$ and $\log 100 \epsilon$ corresponding to these wave lengths for the metal and series of determinations indicated at the head of each double column.

TABLE I.

Summary of Absorption Spectra of Metals in Ammonia.

\begin{tabular}{|c|c|c|c|c|c|c|c|c|c|c|c|}
\hline \multirow{2}{*}{\multicolumn{2}{|c|}{$\begin{array}{c}\lambda_{\text {. }} \\
4 \mu \text { ). } \\
480\end{array}$}} & \multicolumn{3}{|c|}{ Li. } & \multicolumn{2}{|c|}{ NaI. } & \multicolumn{2}{|c|}{ NaII. } & \multicolumn{3}{|c|}{ NaIII. } \\
\hline & & c. & \multicolumn{2}{|c|}{$\log 100 \epsilon$} & I. 35 & $\begin{array}{l}\log 100 \epsilon \\
\text { I , I } 30\end{array}$ & $\epsilon$. & $\begin{array}{c}\log 100 e \\
\ldots\end{array}$ & \multicolumn{2}{|c|}{$\begin{array}{c}e . \\
0.409\end{array}$} & $\begin{array}{l}\log 100 e . \\
0.612\end{array}$ \\
\hline 491 & \multicolumn{2}{|c|}{0.560} & \multicolumn{2}{|c|}{0.748} & $\ldots$ & $\ldots$ & $\ldots$ & $\ldots$ & \multicolumn{2}{|c|}{$\ldots$} & $\ldots$ \\
\hline 502 & \multicolumn{2}{|c|}{$0.5^{85}$} & \multicolumn{2}{|c|}{0.767} & 1.48 & I. I 70 & 0.596 & 0.775 & \multicolumn{2}{|c|}{0.464} & 0.667 \\
\hline 515 & \multirow{2}{*}{\multicolumn{2}{|c|}{$\cdots$}} & \multicolumn{2}{|c|}{$\ldots$} & . & $\ldots$ & 0.636 & 0.804 & \multicolumn{2}{|c|}{$\ldots$} & $\ldots$ \\
\hline 529 & & & \multicolumn{2}{|c|}{0.806} & $x .73$ & 1. 328 & 0.682 & 0.834 & \multicolumn{2}{|c|}{0.496} & 0.696 \\
\hline 547 & \multicolumn{2}{|c|}{0.698} & \multicolumn{2}{|c|}{0.844} & $\ldots$ & $\ldots$ & 0.728 & 0.862 & \multicolumn{2}{|c|}{$\ldots$} & $\ldots$ \\
\hline 564 & \multicolumn{2}{|c|}{0.732} & \multicolumn{2}{|c|}{0.865} & . & $\ldots$ & 0.745 & 0.872 & .. & & $\ldots$ \\
\hline 585 & & 837 & & 923 & . & $\ldots$ & 0.880 & 0.945 & . & & $\ldots$ \\
\hline 608 & & 926 & & 967 & .. & $\ldots$ & 0.990 & 0.996 & 0.7 & & 0.877 \\
\hline 635 & & 029 & & 009 & . & $\ldots$ & $\ldots$ & $\ldots$ & 0.8 & & 0.935 \\
\hline 664 & & $24 \mathrm{I}$ & & 093 & . . & $\ldots$ & $\ldots$ & $\ldots$ & & & $\ldots$ \\
\hline 698 & & 469 & & 167 & . & $\ldots$ & $\ldots$ & $\ldots$ & .. & & $\ldots$ \\
\hline & & $\mathbf{K}$ & & & $\mathbf{K}_{\mathrm{II}}$. & & $\mathbf{K}_{\mathrm{III}}$ & & Mg. & & $\mathrm{Ca}$. \\
\hline in $\mu \mu$ ). & e. & & $100 \varepsilon$. & t. & $\log 100 \mathrm{e}$ & $\overline{l e .}_{\epsilon .}$ & $\log 100 \epsilon$ & 6 & $\log 1006$ & . & $\log 1006$ \\
\hline 480 & 0.747 & & .873 & $\ldots$ & . & o. 192 & 0.283 & 0.529 & 0.724 & $\ldots$ & $\ldots$ \\
\hline $49 \mathrm{I}$ & $\ldots$ & & $\ldots$ & $\ldots$ & $\cdots$ & $\ldots$ & $\ldots$ & $\ldots$ & $\ldots$ & 0.382 & $0.5^{82}$ \\
\hline 502 & 0.804 & & .905 & $\ldots$ & $\cdots$ & 0.232 & 0.366 & $0.5^{87}$ & 0.769 & 0.403 & 0.605 \\
\hline 515 & $\ldots$ & & $\cdots$ & $\ldots$ & $\ldots$ & $\ldots$ & $\ldots$ & $\ldots$ & $\ldots$ & 0.429 & 0.633 \\
\hline 529 & 0.885 & & 947 & 0.313 & 0.496 & 0.255 & 0.407 & 0.684 & 0.835 & 0.459 & 0.662 \\
\hline 547 & $\ldots$ & & $\cdots$ & $\ldots$ & $\ldots$ & $\ldots$ & $\ldots$ & $\ldots$ & & 0.515 & 0.712 \\
\hline 564 & I.046 & & .020 & $\ldots$ & $\ldots$ & 0.296 & 0.471 & 0.769 & 0.886 & 0.567 & 0.754 \\
\hline 585 & $\ldots$ & & $\ldots$ & . & $\ldots$ & $\ldots$ & $\ldots$ & $\ldots$ & $\ldots$ & 0.663 & 0.822 \\
\hline 608 & 1.370 & & 137 & $\ldots$ & $\ldots$ & 0.378 & 0.578 & 1.014 & I. 006 & 0.768 & 0.885 \\
\hline 635 & I. 589 & & 201 & 0.521 & 0.717 & $\ldots$ & $\ldots$ & $\ldots$ & $\ldots$ & 0.917 & 0.962 \\
\hline 664 & 政 & & $\ldots$ & 0.606 & 0.783 & $0.5 \mathrm{II}$ & 0.708 & $1.24 \mathrm{I}$ & I.094 & I.12I & 1.050 \\
\hline 698 & $\ldots$ & & $\ldots$ & $0.73 \mathrm{I}$ & 0.864 & 0.637 & 0.804 & $\ldots$ & $\ldots$ & I. 135 & I.132 \\
\hline
\end{tabular}

In Fig. 6 the values of $\lambda$ from Table $I$ are plotted as abscissas against the values of $\log$ IOOE as ordinates. With the exception of the curve for 
calcium the graphs are all approximately parallel straight lines. This is what we should expect if the coloring principle were the same in all cases, and if the index of absorption were proportional to the concentration of these common coloring molecules, in other words, if they obeyed Beers' law. For if Beers' law is obeyed the ratio $\epsilon_{1} / \epsilon_{2}=$ conc. $1 /$ conc. 2

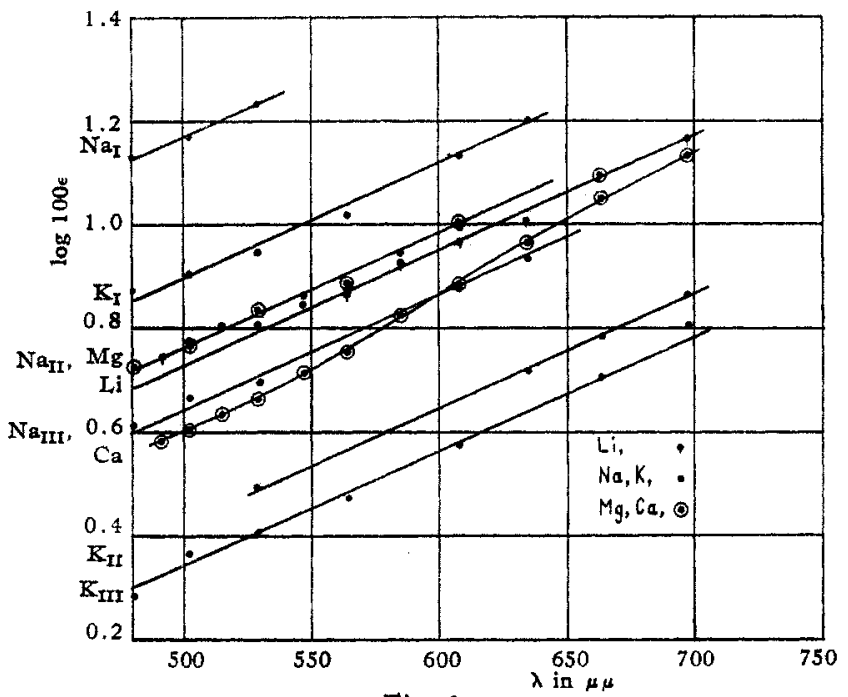

Fig. 6.

depends only on the concentration ratio and is therefore independent of the wave length. Similarly, $\log \epsilon_{1}-\log \epsilon_{2}=\log$ conc. $_{1} /$ conc. ${ }_{2}$ is independent of wave length for the same reason. Hence if we plot $\log \epsilon$ against $\lambda$ for varying concentrations of a coloring substance which obeys Beers' law, we shall obtain curves which are identical in shape and which can all be made to coincide by a displacement parallel to the axis of $\log \epsilon$. Compliance with this condition in the above case does not, however, necessarily show that Beers' law would hold with respect to the total dissolved metal. Thus, if the color were due solely to dissociated solvated electrons, but the dissociation of the metal into electrons were not complete, the concentration of electrons would not be proportional to the concentration of total dissolved metal; the curves of $\log \epsilon$ against $\lambda$ would then satisfy the above criterion if Beers' law held for the dissociated electrons, in which case it clearly could not hold for the total dissolved metal. It is not, however, justifiable to conclude that dissociation into electrons must be complete if Beers' law is obeyed for the total dissolved metal. Thus many solutions of colored inorganic salts obey Beers' law with respect to the total concentration of dissolved salt and are nevertheless far from completely dissociated into ions. In these cases the ionized and un-ionized molecules probably contribute equally to the absorption 
of light. It is possible that we might have a similar phenomenon in the case of dissolved metals. Thus the solvated electrons, to which, as we shall show, the color is probably due, may behave, together with the ions of the metal, in the same manner as the ions of such a salt. We might therefore find the index of absorption to be proportional to the total concentration of dissolved metal, while conductance measurements, for example, indicated incomplete ionization. So far the data are inadequate to decide this question. In our former paper ${ }^{1}$ we showed that Beers' law is obeyed at least approximately by solutions of sodium and potassium at concentrations in the neighborhood of $0.00 \mathrm{r} N$. At these concentrations dissociation into electrons is probably nearly complete. By dilution measurements of solutions of sodium and potassium in liquid ammonia, which we shall not describe in detail, it was found that the same depth of total color to the eye was obtained with solutions of the same molal concentration at $0.0025 M$, with a mean deviation of $0.0003 M$ in 5 determinations. This concentration gave a depth of total color equal to that of a saturated solution of magnesium in ammonia. These are the only direct concentration measurements which have yet been made with liquid ammonia as solvent.

It has already been stated that the absorption spectrum of calcium in liquid ammonia appears to deviate in type from those of the other metals (see Fig. 6). There is an indication of increased absorption at the longer wave lengths. Additional measurements are necessary, however, to confirm this observation, which is based on a single series of measurements with a single solution. It is possible that the deviation in this case may have been due to impurities present in the sample of calcium used. $^{2}$

In experiments which we shall describe presently it was found that the absorption spectrum of sodium in methylamine is very markedly affected by the presence of impurities. It seems possible, therefore, that the absorption spectrum of pure calcium would not differ from those of the other metals. Unfortunately, the investigation had to be interrupted before this question could be definitely decided.

In Table II are given the data from which the values of $\epsilon_{0}$ for liquid ammonia were calculated. The first and second columns explain themselves, the third and fourth columns contain the values of $\alpha_{2}$ and $\alpha_{1}$ (see page $\times 337$ ), each figure being the mean of 16 settings of the instrument. The absorption cell in these measurements contained pure anhydrous ammonia, and the cooling bath (in this as in all other determinations)

1 Loc. cit.

2 This sample was the same as that used by Eastman and Rodebush in their specific heat measurements. It contained $97.75 \% \mathrm{Ca}, 0.85 \% \mathrm{Cl}, 1.08 \% \mathrm{Fe}_{2} \mathrm{O}_{3}$ and $\mathrm{Al}_{2} \mathrm{O}_{3}$, and a trace of $\mathrm{Mg}$. (This JourNaL, 60, 496 (1918).) 
consisted of a mixture of 3 volumes of ether to I volume of alcohol. The last column contains the values of $\epsilon_{0}$ calculated from the values of $\alpha_{2}$ and $\alpha_{1}$ by the equation

$$
\epsilon_{\circ}=\frac{\log \tan \alpha_{2}-\log \tan \alpha_{1}}{1.036} .
$$

The values of $\epsilon_{\circ}$ in parenthesis were obtained by graphical interpolation and extrapolation. The temperature of the cooling bath was approximately $-58^{\circ}$.

TABLE II.

$\epsilon_{0}$ Values for Liquid Ammonia.

\begin{tabular}{|c|c|c|c|c|}
\hline Reading No. & $\lambda$ in $\mu \mu$. & $\alpha_{2}$ & $\alpha_{\mathrm{l}}$ & $t_{0}$ \\
\hline$\ldots$ & 480 & $\ldots$ & . & $(0.216)$ \\
\hline . & $49 \mathrm{I}$ & . & . & $(0.2 \times 1)$ \\
\hline I & 502 & $45^{\circ} 49^{\prime}$ & $32^{\circ} 7^{\prime}$ & 0.207 \\
\hline . & 515 & . & .. & $(0.204)$ \\
\hline 2 & 530 & $4^{\circ}{ }^{\circ} 15^{\prime}$ & $32^{\circ} 58^{\prime}$ & 0.200 \\
\hline . & 547 & . & . & $(0.197)$ \\
\hline . & 564 & $\ldots$ & . & $(0.194)$ \\
\hline$\cdots$ & 585 & $\ldots$ & . & $(0.192)$ \\
\hline 3 & 608 & $47^{\circ} 15^{\prime}$ & $34^{\circ} 29^{\prime}$ & 0.190 \\
\hline . & 63.5 & . & . & $(0.189)$ \\
\hline 4. & 664 & $47^{\circ} 53^{\prime}$ & $35^{\circ} 14^{\prime}$ & 0.188 \\
\hline . & 680 & . & . & $(0.188)$ \\
\hline . & 698 & . & . & $(0.187)$ \\
\hline
\end{tabular}

In Table III are given in detail the data for lithium, potassium and calcium in liquid ammonia. The first column contains the name of the metal and the number of the series of determinations, together with the rate of fading in per cent. of $\epsilon$ per minute, and the temperature coefficient $\partial \ln \epsilon / \partial T$. The latter was determined in only one case $\left(\mathrm{K}_{\mathrm{II}}\right)$ and found to be negligible. The effect of temperature is probably very small in all cases and certainly does not alter the type of absorption spectrum obtained, since the newer determinations at $-50^{\circ}$ and $-60^{\circ}$ give curves of $\log \epsilon$ against $\lambda$, which can be superimposed on those for magnesium (room temperature) and sodium $\left(-35.6^{\circ}\right)$ published in our previous paper. The second and third columns explain themselves, the fourth contains the time of reading the spectrophotometer, and the fifth the temperature of the bath. The sixth and seventh columns contain the readings $\alpha_{4}$ and $\alpha_{3}$ of the analyzer, and the eighth the values of $\epsilon_{1}$ calculated from these values by the equation

$$
\epsilon_{1}=\frac{\log \tan \alpha_{4}-\log \tan \alpha_{3}}{1.036}
$$

The ninth column contains the values of $\epsilon_{\circ}$ taken from Table II, and the tenth the values of $\epsilon_{1}-\epsilon_{0}$. The eleventh column contains the fading correction, and the twelfth the corrected values of $\epsilon$ obtained by adding the fading correction to the valves of $\epsilon_{1}-\epsilon_{0}$ in column ten. 


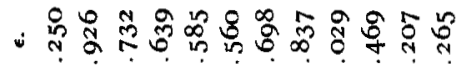
m $00000000 m m$

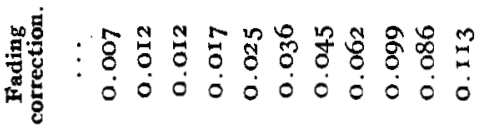

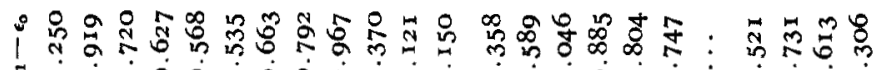

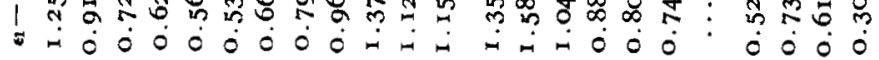

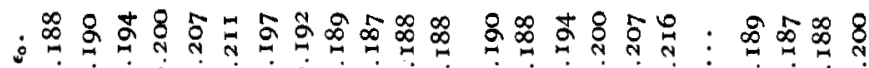

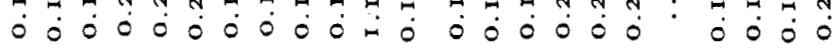

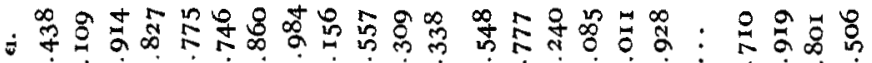

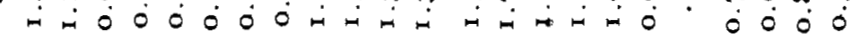

8

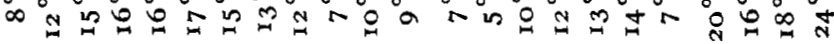
.

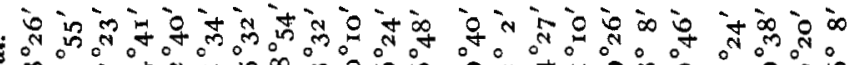

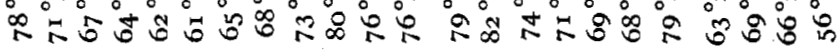

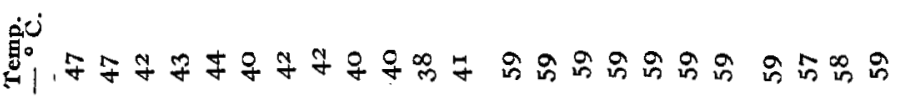

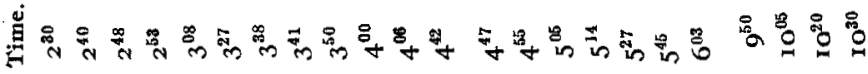

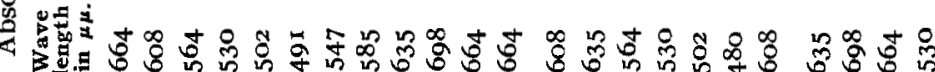

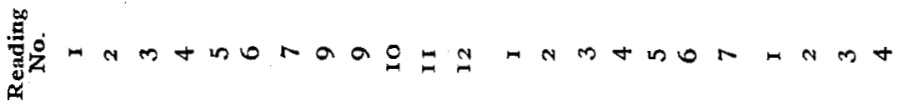

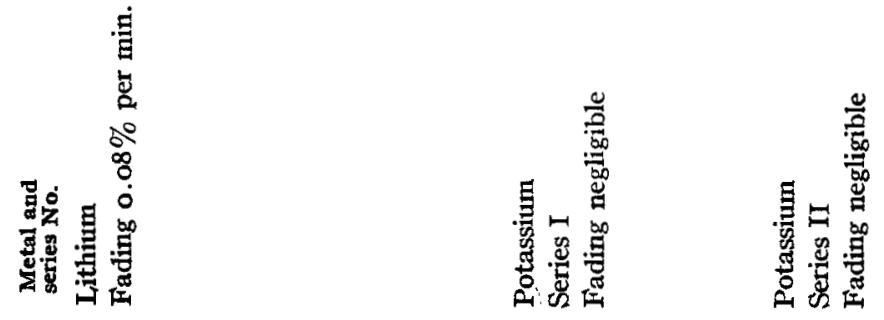




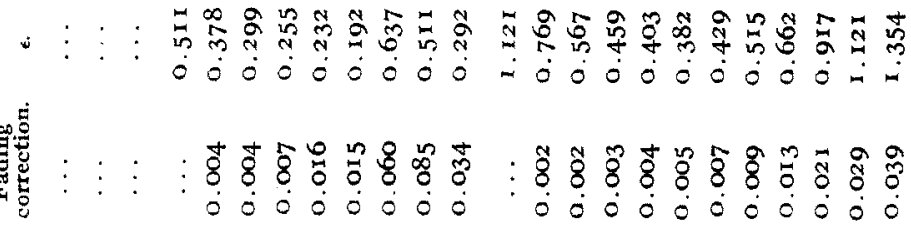

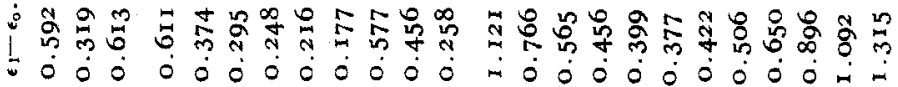

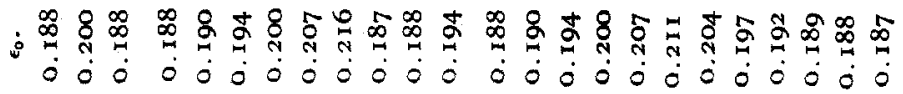

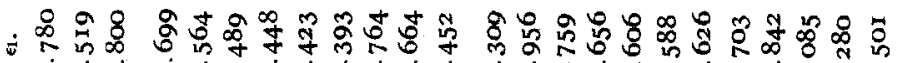

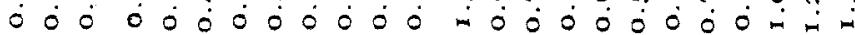

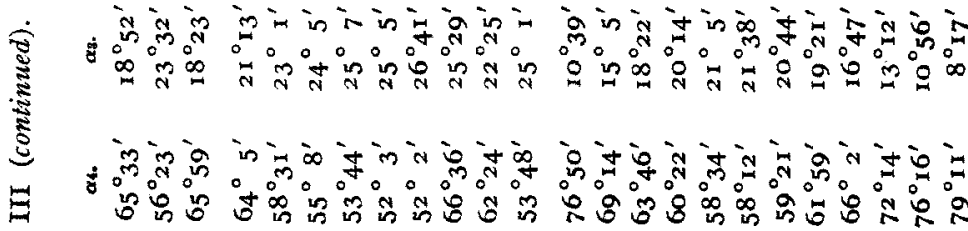

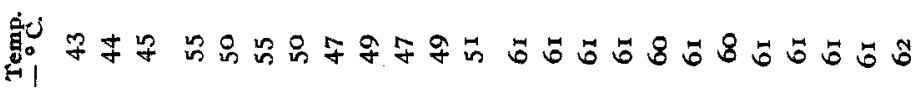

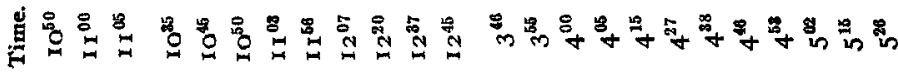

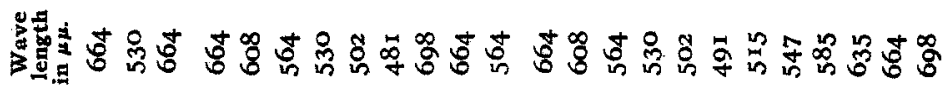

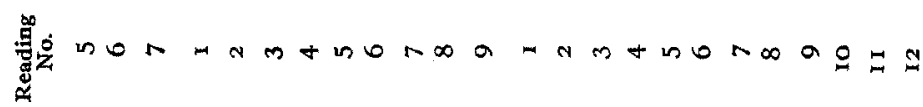




\section{The Absorption Spectra of Lithium, Sodium, Potassium, Caesium} and Calcium Methylamine.

The absorption spectra in methylamine are entirely different in type from those in ammonia. The curves of $\log 100 \epsilon$ against $\lambda$ (see Fig. 7) all show decided absorption maxima at the same wave length, about $65^{\circ} \mu \mu$. The curves, however, cannot be brought to complete coincidence by a displacement parallel to the axis of $\log \epsilon$, as was the case in ammonia. For a limited range in the neighborhood of the band maximum the curves are superimposable within the limits of error, but at

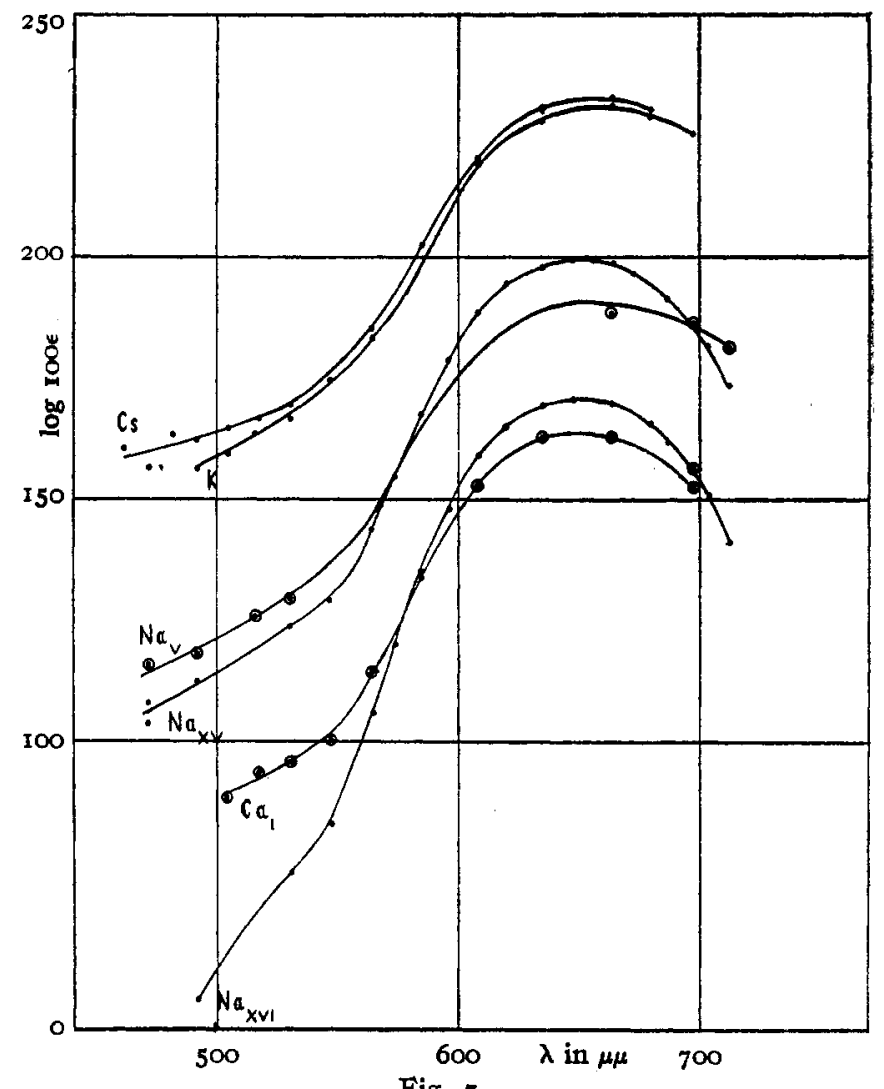

Fig. 7 .

shorter wave lengths deviations become apparent. Thus the curve CaI intersects the curve $\mathrm{Na}_{\mathrm{xvI}}$ in Fig. 7. We might at first sight be led to attribute this to a specific influence of the metal on the nature of the absorption curve. This conclusion is not necessarily correct, however, since it is possible, by varying the experimental conditions, to obtain absorption curves for sodium alone, which differ more from one another than the curves $\mathrm{Ca}_{I}$ and $\mathrm{Na} \mathrm{xvI}_{\mathrm{X}}$ in the figure. 
8

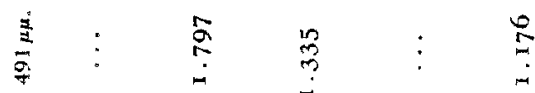

$\begin{array}{llll}0 & \infty & 0 \\ 3 & 0 & 0 & 0 \\ 0 & 0 & 0\end{array}$

$\stackrel{\infty}{\circ}$

in - $i$

$\begin{array}{ll}i & 0 \\ 0 & \infty \\ 0 & \infty\end{array}$

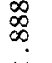

$\frac{1}{4}$

s.

is

站

i.

里

i ल

i

$\frac{20}{6}$

2
2

1
$\frac{1}{2}$
0
0

$\stackrel{\infty}{\infty}$

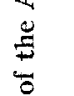

वे

曾

$\frac{3}{5}$

包:

ำ

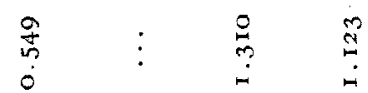

\% $\stackrel{\infty}{m} \stackrel{m}{m}$

0
8
0
0

0

$\dot{0}$

i

2

0

î̀

เูก

$\stackrel{-}{q}$

in

$\infty$

要每

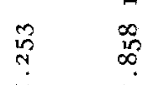

$\stackrel{-1}{+}$

$\stackrel{2}{2}$

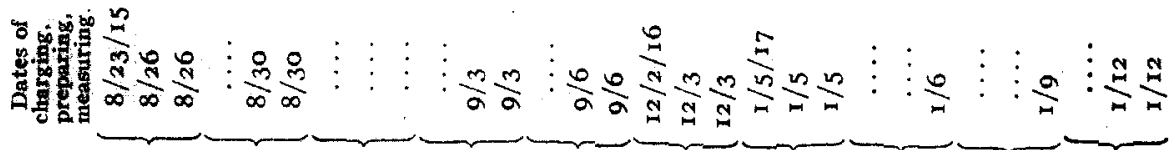

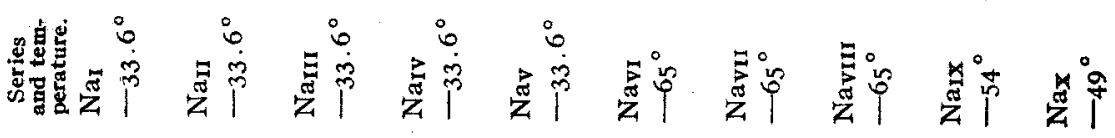


ABSORPTION SPECTRA OF SOLUTIONS OF LIQUID AMMONIA, ETC. I347

$\stackrel{5}{?}$

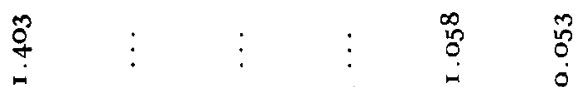

$\stackrel{9}{\stackrel{9}{+}}$

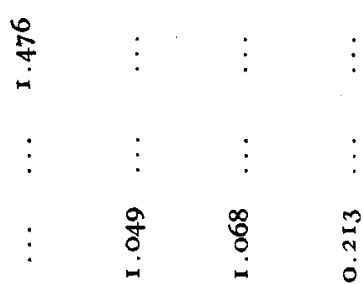

i⿱宀

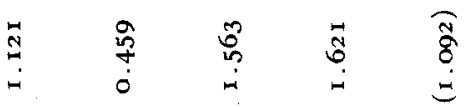

$\vdots \quad \vdots \quad \overbrace{i}^{\infty} \quad$

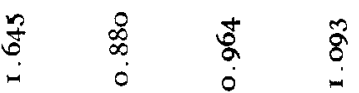

ì

ติ

ลิ

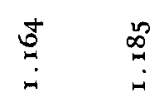

ڤै

ֻ

2

- 0

$\stackrel{\infty}{?}$

8

s

‡

i

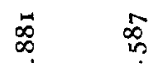

जै ڤू

品

$\stackrel{5}{a}$

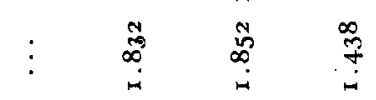

$\infty$

$\stackrel{\infty}{\stackrel{0}{\alpha}}$

s.

๙ั)

$\stackrel{\infty}{0}$

ș

g

$\begin{array}{ll}0 & \infty \\ ? & 0 \\ ? & ?\end{array}$

षे

$\infty$

กับ

000

$\circ$

$\dot{0} \infty$

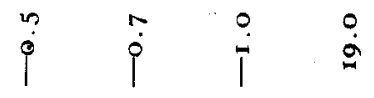

$\vdots \vdots$ :

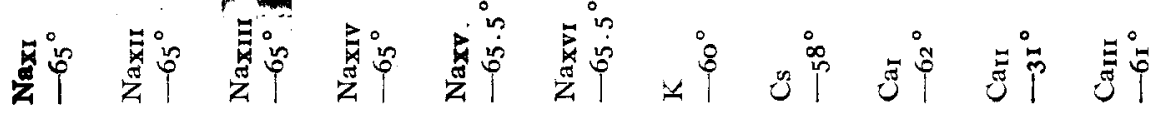


An example of this is also shown in Fig. 7 , where the curves $\mathrm{Na}_{\mathrm{v}}$ and $\mathrm{Na}_{\mathrm{Xv}}$ intersect in much the same manner as $\mathrm{Ca}_{I}$ and $\mathrm{Na} a_{\mathrm{XvI}}$. In order to investigate this behavior, a large number of determinations were made with sodium alone, under varying conditions of temperature, concentration and purity. Sodium was chosen for this purpose, because its low solubility facilitates the preparation of solutions of the right concentration for a measurement. The results of these experiments are contained in the first part of Table IV. Col. I contains the series number and the temperature of the determinations. Col. II contains for each series the date on which the cell was charged with metal and methylamine, the date on which the solution was prepared within the cell, and the date of the actual measurements. Col. III contains the rate of fading in units of $\log \epsilon$ per minute multiplied by ${ }^{4}$. At the head of each of the remaining columns is the wave length in $\mu \mu$, and under each wave length the values of $\log 100 \epsilon$ corresponding to the series numbers in Col. I.

In preparing a solution of a metal in methylamine it is almost impossible to avoid the formation of a considerable amount of a reaction product of the metal with the solvent. Thus a solution prepared in the ordinary manner at room temperature fades rapidly, the reaction most probably being the formation of methylamide according to the equation

$$
\mathrm{Me}+\mathrm{CH}_{3} \mathrm{NH}_{2}=\mathrm{Me}^{+}+\mathrm{CH}_{3} \mathrm{NH}^{-}+{ }^{1 / 2} \mathrm{H}_{2} \text {. }
$$

Kraus has shown that the corresponding reaction in ammonia is very greatly accelerated by the product of the reaction, namely, amide of the metal. We have observed a similar phenomenon in methylamine, solutions which have stood for some time in contact with the metal fading much more rapidly than freshly prepared solutions. We may take the rate at which a solution fades as a qualitative measure of the amount of methylamide which it contains. We should not expect, however, any exact quantitative relationship between the two in our experiments since other impurities, such as hydroxide of the metal, which also act as catalysts, were not entirely excluded. The influence on the absorption curve of the concentration of amide and other impurities as measured roughly by the rate of fading of the solution is shown in Fig. 8, in which the value of $\epsilon$ at the absorption maximum $(650 \mu \mu)$ is plotted against the corresponding value at $530 \mu \mu$ for those series in which measurements at both wave lengths were available. The data from which the plot was made are collected in Table V. Col. I contains the title of the series, Col. II the temperature in degrees below $0^{\circ}$, Col. III the rate of fading as in Table IV, and the remaining two columns the values of $\varepsilon_{650}$ and $\epsilon_{530}$, corresponding to the series designated in Col. I. 
ABSORPTION SPECTRA OF SOLUTIONS OF LIQUID AMMONIA, ETC. I 349

TABLE V.

Sodium in Methylamine.

Effect of Impurities on the Absorption Index.

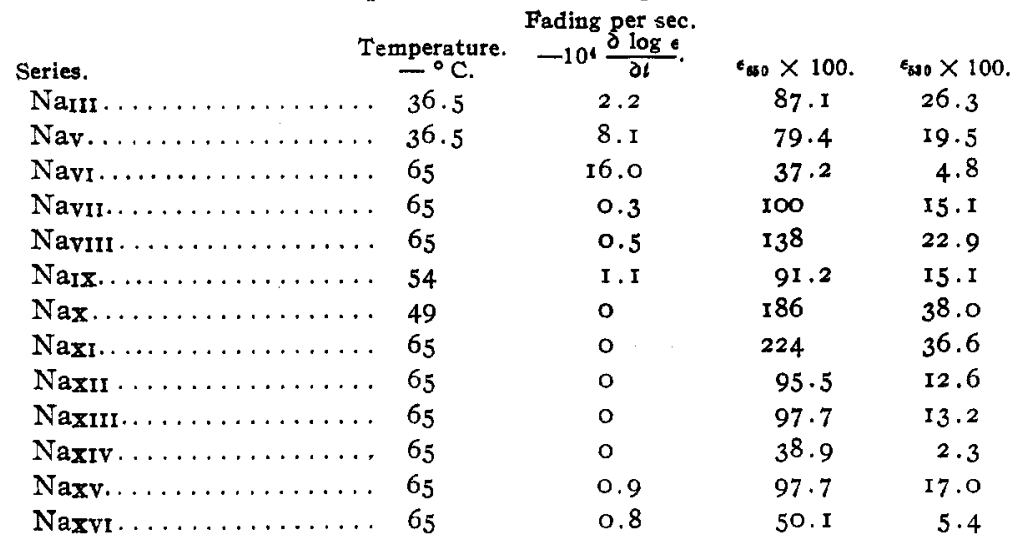

In Fig. 8 those points for which the rate of fading $\partial \log \epsilon / \partial t$ was greater than $10^{-4}$ per minute are enclosed in circles, those in which the rate of fading was less than $10^{-4}$ per minute, but still appreciable, are enclosed in squares, while the plain points indicate zero fading. Series determined at temperatures higher than $-65^{\circ}$ are marked in addition with a cross.

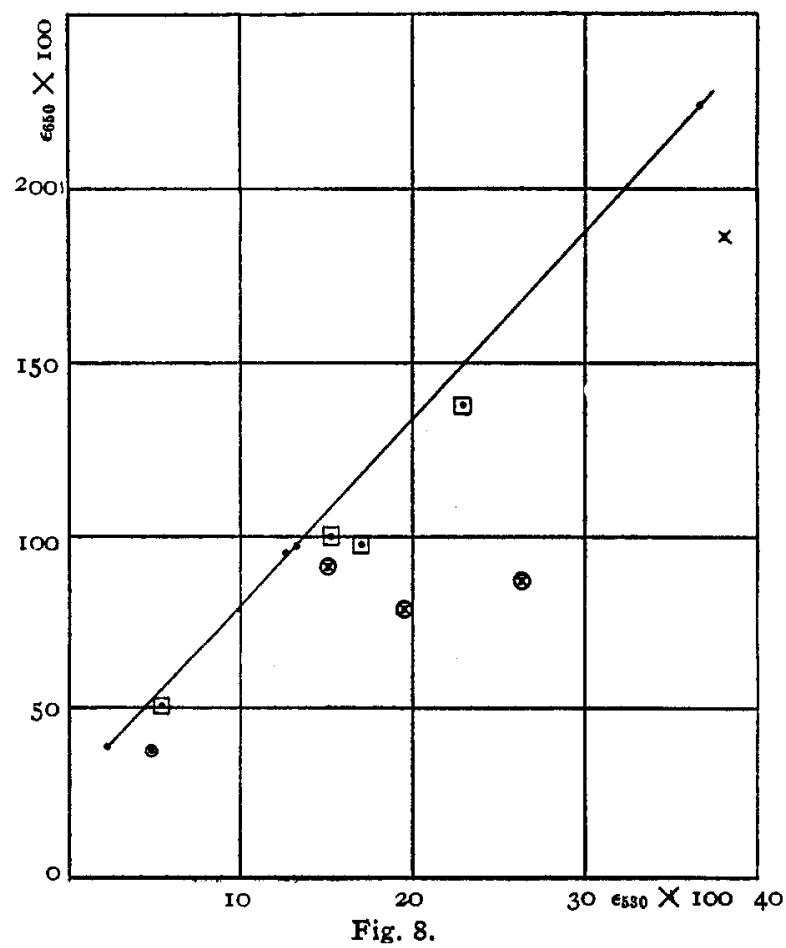


The points of zero fading at $-65^{\circ}$ lie very closely on a straight line, which, however, does not go through the origin as would be required by Beers' law. 'The effect of an increase in temperature (Series $\mathrm{X}$ ) is to increase the absorption in the blue relative to the absorption in the red, so that the point is displaced to the right of the straight line. Increase in rate of fading has the same effect. The combined effects of fading and temperature increase is shown in Series III and V, which lie furthest to the right of all. We have already mentioned that the curves of $\log \epsilon$ against $\lambda$ are superimposable in the neighborhood of the band maximum which is in agreement with the supposition that the absorption at those wave lengths is mainly due to a single substance (probably solvated electron) which obeys Beers' law. We may therefore account for the deviations from Beers' law at the shorter wave lengths by assuming the presence of two substances in the solution, each of which separately obeys Beers' law. One of these is responsible for the absorption at the band maximum, and is the main constituent of the solution at low concentrations. The other absorbs only slightly at the band maximum, but more markedly at the shorter wave lengths, and increases in amount relatively to the first as the total concentration of the solution is increased.

This assumption may be tested in the following manner: Let $c^{\prime}$, $c^{\prime \prime}$ denote the concentrations of the two substances and $\epsilon_{\circ}{ }^{\prime}$ and $\epsilon_{0}{ }^{\prime \prime}$ their molecular absorption indices, $i$. $e$., the absorption indices of solutions containing each of the substances separately in normal concentration (one mol. per liter). The absorption index of a solution of total concentration $c_{1}=c_{1}^{\prime}+c_{1}^{\prime \prime}$ is then

$$
\epsilon_{1}=\epsilon_{0}{ }^{\prime} C_{1}{ }^{\prime}+\epsilon_{\circ}{ }^{\prime \prime} C_{1}{ }^{\prime \prime} .
$$

Similarly, at total concentration $c_{2}$, we have

$$
\epsilon_{2}=\epsilon_{0}{ }^{\prime} C_{2}{ }^{\prime}+\epsilon_{0}{ }^{\prime \prime} c_{2}{ }^{\prime \prime} \text {. }
$$

Equations $x$ and 2 must hold at any wave length. Multiplying (2) by $c_{1}^{\prime} / c_{2}^{\prime}$ and subtracting from ( $\mathrm{I}$ ) we obtain

$$
\epsilon_{1}-\frac{c_{1}^{\prime}}{c_{2}^{\prime}} \epsilon_{2}=\epsilon_{0}^{\prime \prime}\left(c_{1}^{\prime \prime}-c_{2}^{\prime \prime} \frac{c_{1}{ }^{\prime}}{c_{2}{ }^{\prime}}\right) .
$$

If Beers' law holds for the solution as a whole at a particular wave length (as in our case at the band maximum), the absorption must be due at that wave length to one substance only, say the substance whose concentration is $c^{\prime}$.

We have then

$$
\frac{c_{1}}{c_{2}}=\frac{\epsilon_{m_{1}}}{\epsilon_{m_{2}}}=\frac{c_{1}^{\prime}}{c_{2}^{\prime}}
$$

where $\epsilon_{m_{2}}, \epsilon_{m_{2}}$ denote the absorption indices of solutions of total concentrations $c_{1}$ and $c_{2}$ for the wave lengths at which Beers' law holds (maximum of the band). Combining (3) and (4), we obtain 


$$
\epsilon_{1}-\frac{\epsilon_{m_{1}}}{\epsilon_{m_{2}}}=a_{12} \epsilon_{\circ}^{\prime \prime}
$$

where $a_{12}=c_{1}^{\prime \prime}-c_{2}{ }^{\prime \prime} c_{1}{ }^{\prime} / c_{2}{ }^{\prime}$ is independent of the wave length, and is constant for a given pair of solutions.

If absorption curves are available at three different concentrations, $c_{1}, c_{2}, c_{3}$, we may combine the first and third in a similar manner and obtain

$$
\epsilon_{1}-\frac{\epsilon_{m_{1}}}{\epsilon_{m_{3}}} \epsilon_{3}=a_{13} \epsilon_{\circ}^{\prime \prime} .
$$

Dividing (5) by (6), we have finally

$$
\frac{\epsilon_{1}-\epsilon_{m_{1}} / \epsilon_{m_{2}} \epsilon_{2}}{\epsilon_{1}-\epsilon_{m_{1}} / \epsilon_{m_{3}} \epsilon_{3}}=\frac{a_{12}}{a_{13}}
$$

Using the contractions $\varphi_{12}(\lambda)$ and $\varphi_{13}(\lambda)$ for the numerator and denominator of the first term of $(7)$, we have now shown that the ratio $\varphi_{12}(\lambda) / \varphi_{13}(\lambda)=a_{12} / a_{13}$ is independent of the wave length, and constant for three given solutions. We may make use of this relationship to test our original assumption. The calculation has been carried out for the series XII, XIV, XV, all of which lie on the curve of zero fading (Fig. 8). The results are given in Table VI. The first column contains the wave lengths in $\mu \mu$. The next three contain the values of $\log _{100_{6}}$ at these wave lengths for the series at the head of each column. Points marked with an asterisk were obtained by graphical interpolation from the figures given in Table IV. The fifth and sixth columns contain the values of

\begin{tabular}{|c|c|c|c|c|c|c|}
\hline & $\begin{array}{l}\text { Ser. XII. } \\
\quad \log \epsilon_{1}\end{array}$ & $\begin{array}{c}\text { Ser. XIV. } \\
\log \epsilon_{2} \text {. }\end{array}$ & $\begin{array}{l}\text { TABLE } \\
\text { Ser. } x V . \\
\log \epsilon_{8} .\end{array}$ & $\begin{array}{l}\text { I. } \\
\varphi_{12}(\lambda)= \\
\epsilon_{1}-\frac{\epsilon m_{1}}{\epsilon m_{2}} \epsilon_{2}\end{array}$ & $\begin{array}{c}\varphi_{18}(\lambda)= \\
e_{1}-\frac{m_{1}}{e m_{3}} e s\end{array}$ & $\varphi_{12}(\lambda) / \varphi_{18}(\lambda)$. \\
\hline $515 \ldots \ldots \ldots \ldots$ & I. $53^{*}$ & I. 068 & $0.2 \mathrm{I} 3$ & 0.058 & $0.24 I$ & $0.24 \mathrm{I}$ \\
\hline $547 \ldots \ldots \ldots \ldots$ & I. $62 *$ & I. 185 & 0.532 & 0.050 & 0.212 & 0.236 \\
\hline $650(\max )$ & $2.38^{*}$ & $2.00^{*}$ & I. $60^{*}$ & $\ldots$ & $\ldots$ & $\ldots$ \\
\hline
\end{tabular}
$\varphi_{12}(\lambda)$ and $\varphi_{13}(\lambda)$ calculated from these data, and the seventh the values of the ratio $\varphi_{12}(\lambda) / \varphi_{13}(\lambda)$.

The ratio is constant within the limits of experimental error.

The quantities $\varphi_{12}(\lambda)$ and $\varphi_{13}(\lambda)$ are both proportional to $\epsilon_{0}$ " by Equations 5 and 6 . The absorption $\epsilon_{0}$ " therefore increases as the wave length is diminished, and is probably due to a substance with an absorption maximum in the ultraviolet. The data are, however, too meagre to be regarded as proving definitely the presence of only two absorbing substances in the solutions. Our experiments unfortunately were interrupted before this point could be decided. If we may be allowed to speculate we may ascribe the absorption in the blue to un-ionized molecules of the metal and the absorption band in the red to the solvated electrons, formed according to the equations 


$$
\begin{gathered}
\mathrm{Na}=\mathrm{Na}^{+}+\ominus \\
\ominus+x \mathrm{CH}_{3} \mathrm{NH}_{2}=\left(\mathrm{CH}_{3} \mathrm{NH}_{2}\right)_{x}{ }^{-} .
\end{gathered}
$$

In support of this hypothesis we have the fact that the absorption in the blue is increased relatively to the absorption at the band maximum by an increase in the total concentration of metal, and also by an increase in the concentration of methylamide, which would repress the ionization on account of the corresponding increase in the concentration of sodium ion. If this explanation is correct we can show that the dissociation of the metal into electrons does not obey the mass law. For if the mass law were obeyed we should have in a pure solution of the metal

$$
\frac{(\mathrm{Na}+) \ominus}{(\mathrm{Na})}=\frac{\Theta^{2}}{\mathrm{Na}}=K \text {. }
$$

Hence if we identify $c^{\prime}$ and $c^{\prime \prime}$ in our previous calculation (p. r35o) with the concentration of electrons $\Theta$ and of un-ionized metal ( $\mathrm{Na}$ ) we obtain $c_{2}{ }^{\prime \prime} / c_{1}{ }^{\prime \prime}={c_{2}}^{\prime 2} / c_{1}{ }^{2}$ and $c_{3}{ }^{\prime \prime} / c_{1}{ }^{\prime \prime}=c_{3}{ }^{2} / c_{1}{ }^{2}$, from which by a simple calculation we obtain for the constant in Table VI the equation

$$
\varphi_{12}(\lambda) / \varphi_{13}(\lambda)=\frac{c_{1}{ }^{\prime}-c_{2}{ }^{\prime}}{c_{1}{ }^{\prime}-c_{3}{ }^{\prime}}=\frac{\epsilon_{m_{1}}-\epsilon_{m_{2}}}{\epsilon_{m_{1}}-\epsilon_{m 3}}
$$

Substituting the values of $\epsilon_{\max }$ from the table we obtain

$$
\varphi_{12}(\lambda) / \varphi_{13}(\lambda)=\frac{2.40-1.00}{2.40-0.40}=\frac{1.4}{2.0}=0.70
$$

instead of the experimental value 0.24 . It is, however, not surprising that the mass law should fail for so polar an electrolyte as metallic sodium. In agreement with this it can also be shown that the mass law would involve a quadratic relationship between $\epsilon_{650}$ and $\epsilon_{530}$ instead of the linear relationship (Fig. 8) which seems to hold even in the most dilute solutions investigated. The curve must, however, pass through the origin since $\epsilon_{650}$ and $\epsilon_{630}$ both vanish at infinite dilution, and it is possible that the mass law may hold at very low concentrations.

The marked negative temperature coefficient of the absorption in methylamine solutions is also of interest in this connection. We might be tempted to ascribe this to a diminution in the degree of ionization of the metal with temperature such as is observed with other strong electrolytes. This would, however, involve an enormously greater diminution in ionization with temperature than is the case in such electrolytes as $\mathrm{KCl}$. It would further demand the presence of a large concentration of un-ionized metal, that is to say only very partial ionization of the metal into electrons and metal ions. Unless the ionization of the metal obeys a very peculiar law, we should not expect the degree of ionization to be independent of concentration unless it is unity or nearly so. This explanation of the negative temperature coefficient would thus lead us to 
expect that the absorption index at the band maximum would diminish more rapidly than the total concentration of sodium, $i$. e., we should not expect direct proportionality between the two. Determinations of the total concentration of metal are not free from difficulty and would have necessitated alterations in our apparatus, for which reason they were left for a future investigation. We were able, however, to determine the relative concentrations of metal in Series $\mathrm{Naxv}$ and $\mathrm{NaxvI}$ calorimetrically in the following manner: The absorption cell at the beginning of the experiment contained an unknown amount of methylamine. The amount of heat necessary to evaporate this completely was first determined by pouring the whole of it into the lower bulb of the apparatus (d, Fig. 4 ), which was immersed in a known volume of alcohol in a Dewar vessel, and distilling off the methylamine by cooling the absorption cell with carbon dioxide snow and ether. The fall in temperature of the alcohol during the distillation was noted. A solution of sodium in methylamine prepared by the method already described was then measured in the absorption cell. The values obtained were those of Series XV.

To prepare the solution for Series XVI a part of solution XV was poured back into the lower bulb $(d)$, warmed rapidly to room temperature, immersed in the same volume of alcohol as before and distilled into the remaining solution in the absorption cell. The solution in the absorption cell was thus diluted by a known amount. If the fall in temperature for distillation of all the methylamine is $t_{1}$, and for the part of the methylamine poured off is $t_{2}$, then the fraction of the sodium poured off is $t_{2} / t_{1}$ of the total, and since the remaining fraction of the sodium $t_{1}-t_{2} / t_{1}$, was again dissolved in all the methylamine, the concentration of the solution is Series XVI was $t_{1}-t_{2} / t_{1}$ times the concentration in Series XV.

In practice it is necessary to make a correction for the slight warming up of the alcohol due to the lack of efficiency of the Dewar vessel. This we did by observing the rates of rise of temperature of the contents from the temperature reached in our experiments to room temperature. The fall in temperature $t_{1}$ in the first distillation was $9.50^{\circ}$ plus the correction $0.30^{\circ}$ for heat leak, i. e., 9.80. In the second distillation the fall in temperature $t_{2}$ was 4.48 plus $0.2^{\circ}, i$. e., 4.68 . The concentration ratio is therefore $(9.80-4.68) / 9.80=0.52$. The corresponding ratio of the absorption indices in Series $\mathrm{NaxvI}$ and $\mathrm{Naxv}$ is 0.513 . The difference between the two is smaller than the possible error of the experiment. The proportionality between the absorption at the maximum and the total concentration of sodium, which we have thus proved, indicates nearly complete dissociation into sodium ions and electrons. It seems unlikely, therefore, that the diminution in absorption with temperature can be due to a diminution in the degree of dissociation. A more plausible explanation of the decrease in absorption with tempera- 
ture is the following: We have shown in our former paper $^{1}$ that the $a b-$ sorption due to unsolvated electrons is probably very small in these dilute solutions. If the dissociation of the solvated electrons into methylamine and unsolvated electrons increases with temperature, the concentration of solvated electrons and hence also the absorption at the band maximum would diminish with temperature as observed. The degree of solvation of the electrons would certainly be practically independent of concentration in such dilute solutions, which would account for the observed proportionality between the absorption at the maximum and the total concentration of metal. The fact that the absorption is practically independent of temperature in liquid ammonia would then indicate that solvation of the electrons is practically complete in that solvent at all temperatures in the range investigated. Absorption measurements of solutions in mixtures of ammonia and methylamine, and conductivity measurements in methylamine might throw some light on this problem.

In our former paper we have shown that Drude's theory of absorption leads to a contradiction with facts if we ascribe the absorption to unsolvated electrons. If the absorption is due to solvated electrons, however, we should be able to calculate their concentration and the damping constant of their vibrations from the theory of Drude. We have performed this calculation for the absorption in the neighborhood of the band maximum in the series $\mathrm{Naxv}_{\mathrm{x}}$. The calculation involves an extension of the theory for heavily damped vibrations. We shall postpone the discussion of this theory, however, until we are able to compare the calculated concentrations with experimental determinations. In the meantime we may say that the theory leads to values of the right order of magnitude.

We shall conclude this section by giving in detail the experimental data for solutions in methylamine of potassium, caesium, calcium, and for the last seven of the sodium determinations, which are more reliable than the earlier series. The data which follow have already been summarized in Table IV.

In Table VII are given the data from which the values of $\epsilon_{\circ}$ for methylamine were calculated. The first is measurements were made with a colorless solution obtained by allowing the blue sodium solution $\mathrm{Na}_{\mathrm{IX}}$ to fade overnight at room temperature. The last two measurements were carried out with pure methylamine prepared by distillation from the same solution. There is a very slight indication of a diminution in absorption in the red after the distillation. This was allowed for in preparing the curve from which the final $\epsilon_{\circ}$ values were interpolated. The interpolated values are not included in Table VII, but were used in the calculations of the subsequent tables. The columns in the table are identical with those in the corresponding table for ammonia (Table II) ${ }^{1}$ Loc. cit. 
with the addition of the temperatures of the determinations in Col. 2 . The temperature coefficient of $\epsilon_{\circ}$ is clearly negligible.

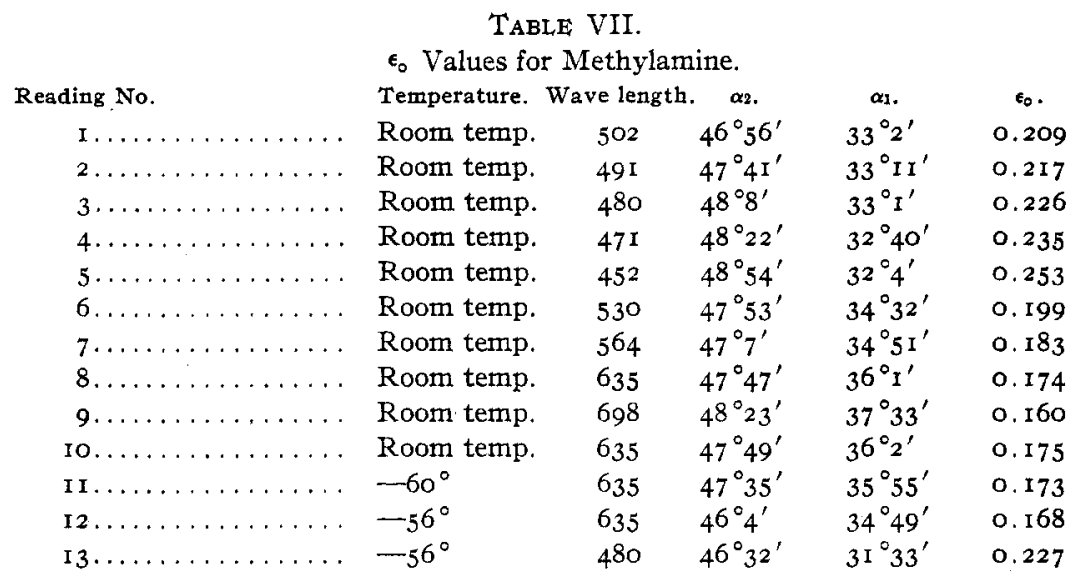

Table VIII contains in detail the data for the last 7 series for sodium and the series for calcium, caesium and potassium. The determinations for the last three metals are less accurate, since the fading correction is negative for all of them. The cause of this increase in absorption with time is not certain, but it was probably due to a minute particle of undissolved metal, which escaped observation when the solutions were prepared. The dissolving of such a particle and the subsequent slow equalization of concentration would produce an increase in absorption of the somewhat irregular character observed. The correction, however, is not very large and the results suffice to show the identity in type of the absorption curves in all cases. In one of the earlier sodium series which we shall not publish, a similar irregular increase in absorption with time was observed. Reading No. I3 for calcium lies very much above the curve drawn through the other points, and while the possibility of a sudden rapid rise in absorption towards the violet is not absolutely excluded, it would seem as if some serious accidental error of unknown origin had been incurred in this one determination.

The first column in Table VIII contains the symbol of the metal and the series number, the second the number of the reading in the series, the third the wave length in $\mu \mu$, the fourth the time of reading, the fifth the temperature in degrees below zero, the sixth and seventh the spectrophotometer readings $\alpha_{4}$ and $\alpha_{3}$ (see p. I337), the eighth the values of $\epsilon_{1}$ calculated from the equation

$$
\epsilon_{1}=\frac{\log \tan \alpha_{4}-\log \tan \alpha_{3},}{1.036}
$$

the ninth the corresponding values of $\epsilon_{0}$, the tenth the difference $\epsilon_{1}-\epsilon_{0}$, the eleventh the logarithms of $\epsilon_{1}-\epsilon_{0}$ multiplied by 100 (to avoid nega- 


\section{$\stackrel{4}{8}$}

然

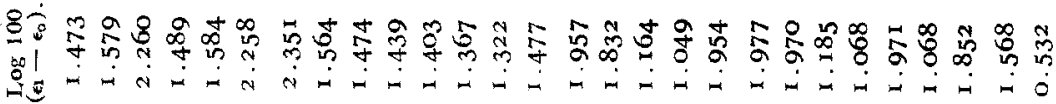

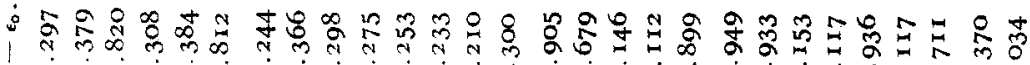

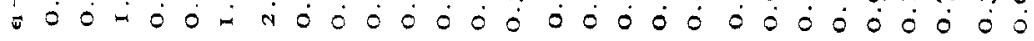

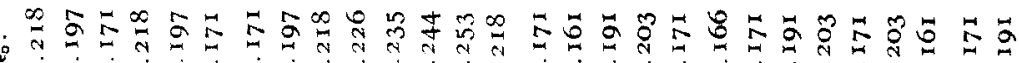

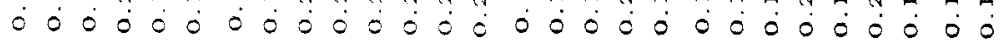

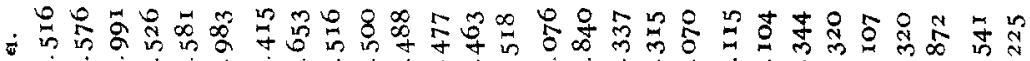

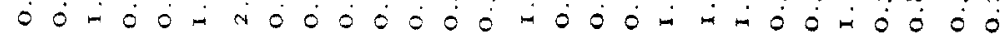

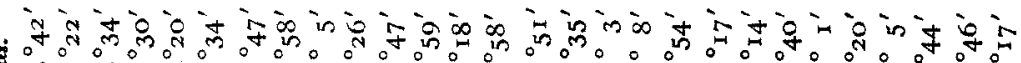

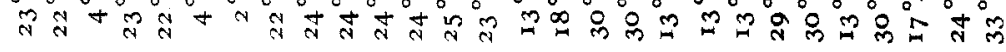
要

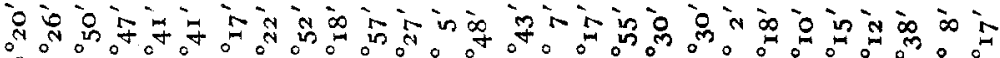

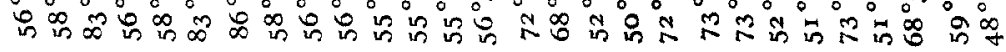
$\Xi$

戬 节 递

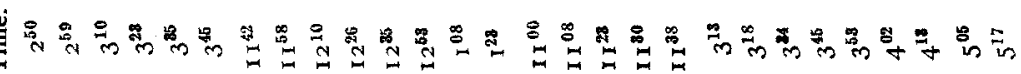

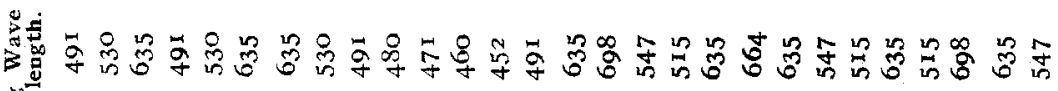

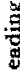

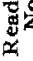

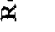




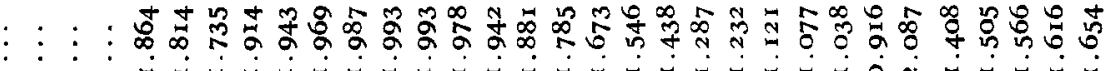

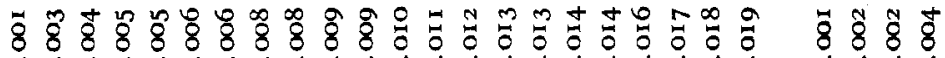
000000000000000000000000000000

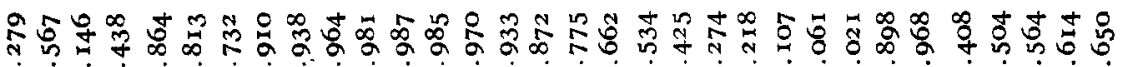

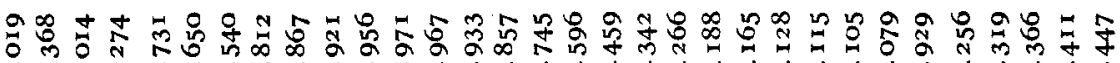
00000000000000000000000000000

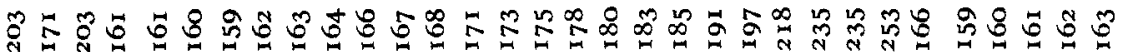

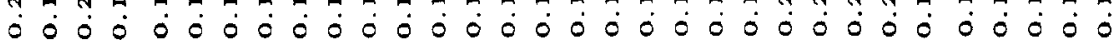

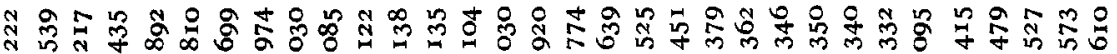

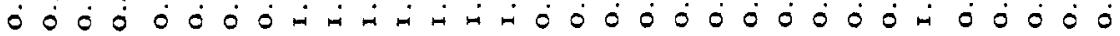

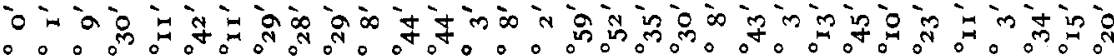

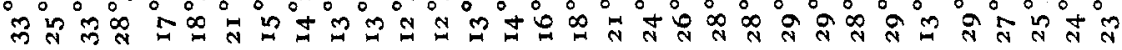

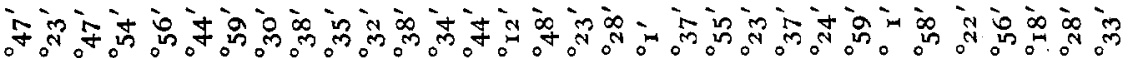

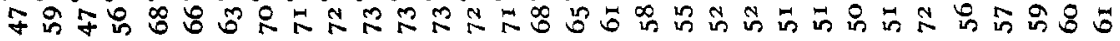

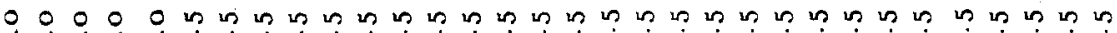
की

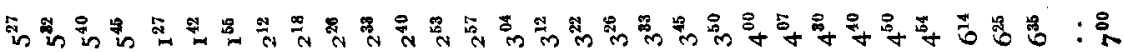

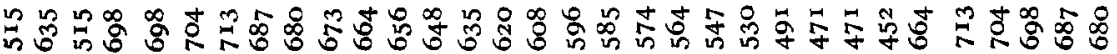

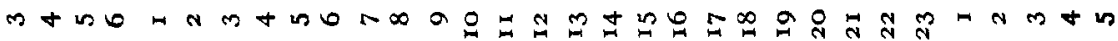


9

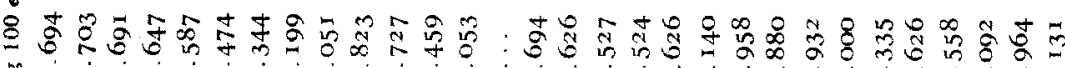

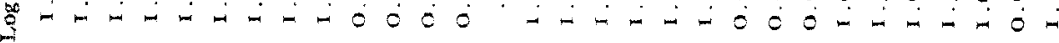

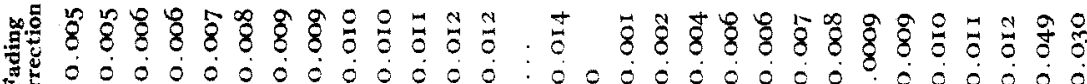

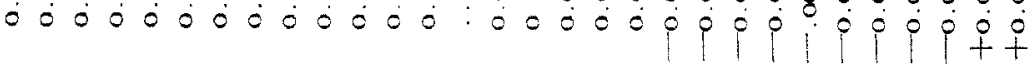

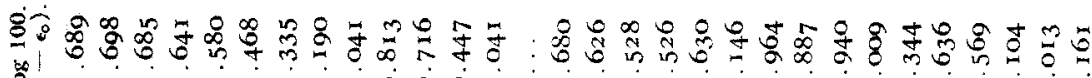

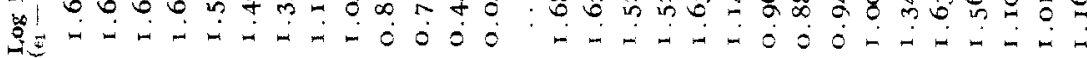

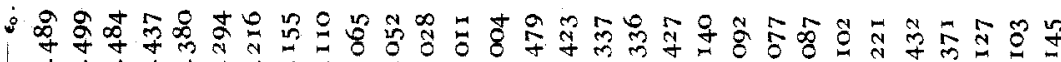

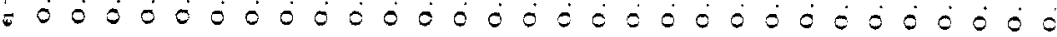

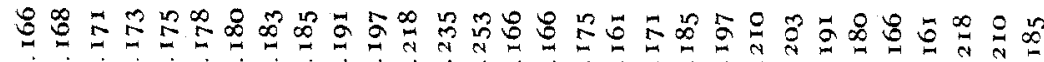

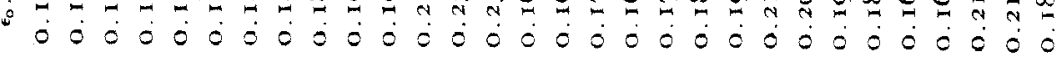

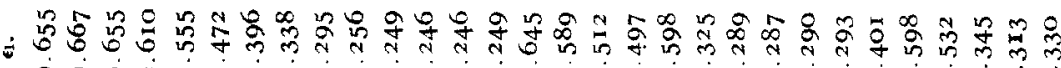
000000000000000000000000000000

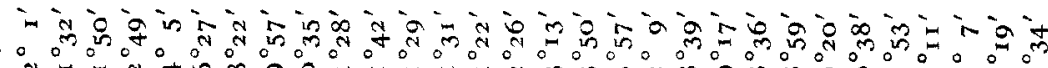

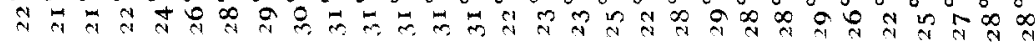
कid 田 洯

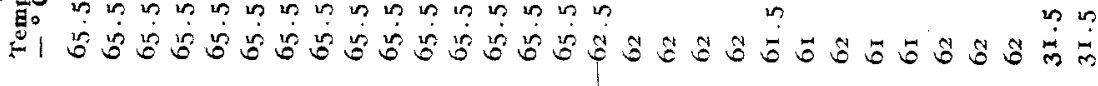

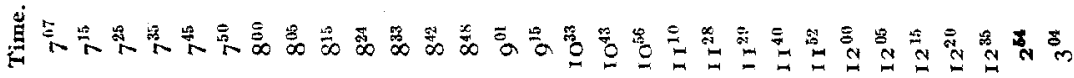

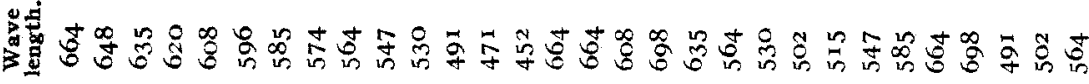

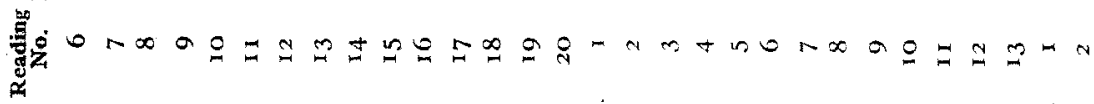

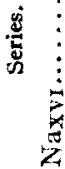

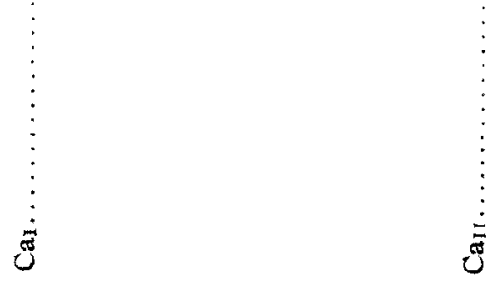




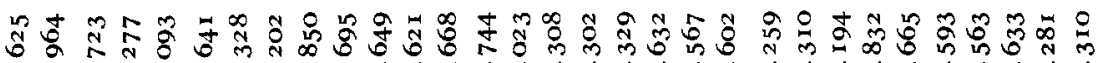

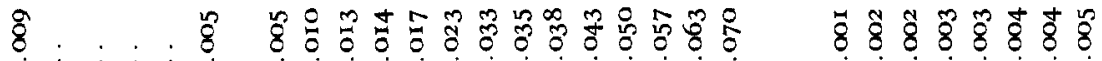

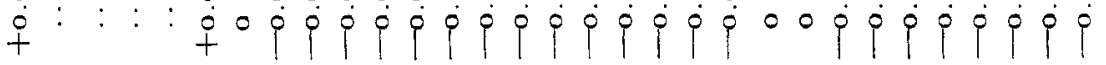

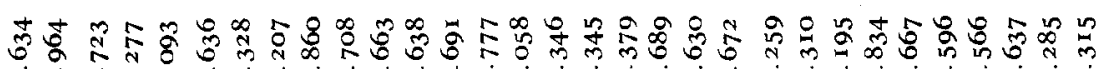

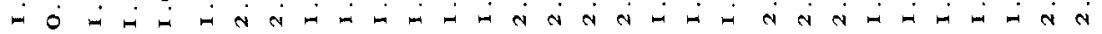

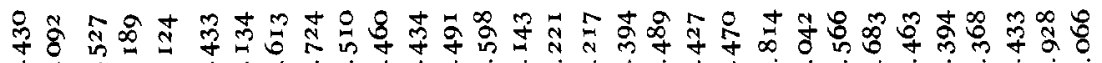

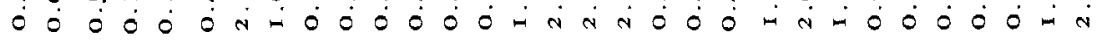

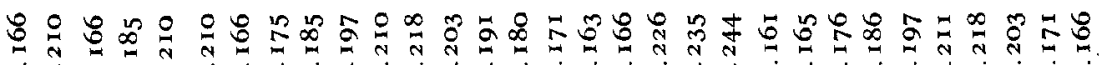

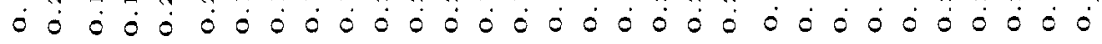

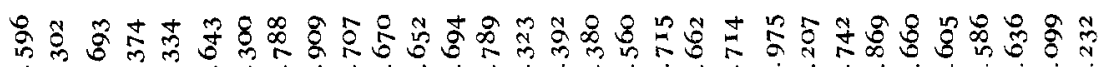

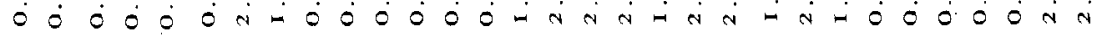

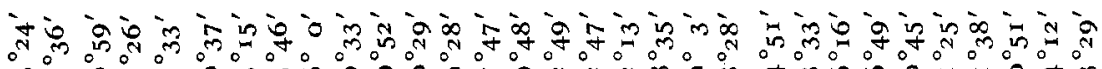

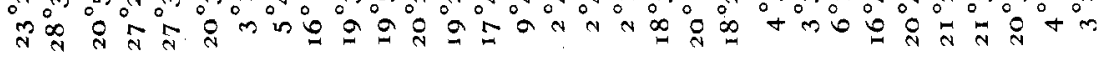

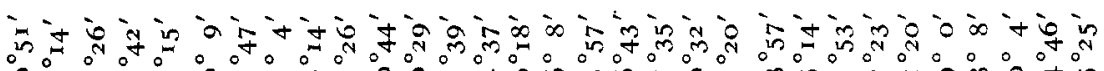

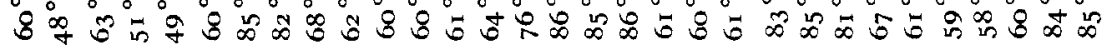

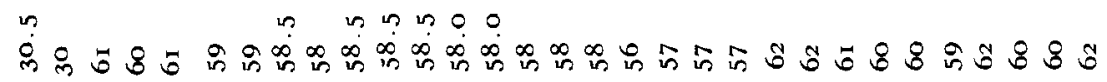

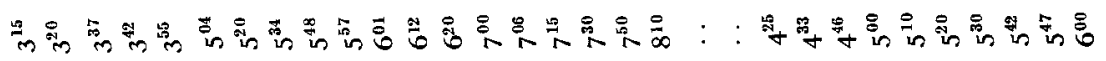

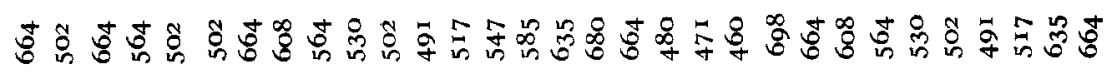

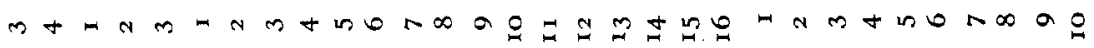


tive characteristics), the twelfth the fading correction in units of $\log \epsilon$, and the thirteenth the corrected values of $\log$ IOOE, obtained by adding the fading correction of the figures in column eleven.

The temperature coefficient of the absorption index may be calculated for calcium from the Series $\mathrm{Ca}_{\mathrm{II}}$ and $\mathrm{Ca}_{\mathrm{III}}$. Thus, at $502 \mu \mu, 5^{6} 4 \mu \mu$ and $664 \mu \mu, \partial \log \epsilon / \partial T=0.0043,0.0049$ and 0.0033 units of $\log \epsilon$ per degree. There is an indication of a greater temperature coefficient at the shorter wave lengths, but the data are not sufficiently reliable to decide this point with certainty. Rough measurements with caesium and sodium gave values of the same order of magnitude. Calculated in per cent. of $\epsilon$ the temperature coefficient is approximately one per cent. per degree.

In the case of lithium the solutions in methylamine faded so rapidly that no accurate absorption measurements were possible. This was probably due to impurities in the only sample of the metal at our disposal. We were able, however, to establish definitely the existence of an absorption maximum in the same region of wave length as that of the other metals.

\section{Summary.}

I. Kraus has shown that the electrical properties of solutions of metals in liquid ammonia can be explained on the assumption that the atoms of the metal dissociate into electrons partly combined with the solvent and into the cations present in liquid ammonia solutions of salts of the metal.

2. In a previous paper by the authors it was shown that the absorption spectra of dilute solutions of sodium and magnesium in liquid ammonia are identical, and the explanation was suggested that the color in both cases is due to the electrons resulting from this dissociation of the metal. With the aid of Drude's theory of metallic absorption it was further shown that the color could not be due entirely to uncombined electrons.

3. In the present paper the absorption measurements have been extended to solutions of lithium, potassium and calcium in liquid ammonia, and lithium, sodium, potassium, caesium and calcium in methylamine. With the possible exception of calcium the solutions in liquid ammonia have identical absorption spectra.

4. In methylamine the absorption spectra are entirely different from those in liquid ammonia, a marked absorption maximum appearing, which is absent in the ammonia solutions. The wave length of the absorption maximum $(650 \mu \mu)$ is, however, independent of the nature of the metal.

5. In liquid ammonia the absorption index is independent of temperature, within the limits of error of the determinations, but in methylamine a marked negative temperature coefficient was observed in all 
solutions investigated, the absorption index diminishing approximately $1 \%$ for a rise in temperature of one degree.

6. In liquid ammonia rough measurements of concentration showed the absorption index to be proportional to the total concentration of metal.

7. In methylamine the absorption index, at the wave length of the band maximum is also proportional to the total concentration of metal. At shorter wave lengths, however, deviations were observed, the absorption increasing more rapidly with concentration than Beers' law would demand. The ratio of the absorption index at $650 \mu \mu$ to that at $530 \mu \mu$ increases not only with increasing concentration of the metal but also with increasing concentration of the reaction product of the metal with methylamine, and probably also with increasing temperature.

8. These observations can be accounted for by the following hypotheses: The color in all cases is due to electrons combined with the solvent. In ammonia the dissociation of the metal into electrons is nearly complete, and the concentration of electrons uncombined with solvent is negligible compared with that of the solvated electrons. In other words, the solvation of the electrons is nearly complete. In methylamine, on the other hand, the concentration of un-ionized metal is no longer negligible and is responsible for the increased absorption at the shorter wave lengths. The solvation of the electrons in methylamine is incomplete and diminishes as the temperature is increased.

Berkeley, Calif.

[CONTRIBUTION FROM THE RESEARCh LABORATORY OF THE GENERAL ELECTRIC Co.]

\section{THE ADSORPTION OF GASES ON PLANE SURFACES OF GLASS, MICA AND PLATINUM. \\ BY IRviNo IANGMUIR. \\ Received June 25, 1918.}

In his studies of the continuous change from the liquid to the vapor state, at temperatures above the critical, van der Waals developed the theory that at the boundary between a liquid and its vapor there is not an abrupt change from one state to the other, but rather that a transition layer exists in which the density and other properties vary gradually from those of the liquid to those of the vapor.

This idea of the continuous transition between phases of matter has been applied very generally in the development of theories of surface phenomena, such as surface tension, adsorption, etc.

Eucken, ${ }^{1}$ for example, in dealing with the theory of adsorption of gases, considers that the transition layer is a sort of miniature atmosphere, the molecules being attracted to the surface by some kind of "action at a

${ }^{1}$ Eucken, Verh. deut. physik. Ges., 16,345 (1914). 